\title{
دور الإدارة المدرسية في هواجهة التسرب الدراسي في المدارس المتوسطة بمحافظة الإحساء
}

إعداد

د. محمد محمود خطاب

باحث تربوي ، القاهرة
د.أحمد عبد الفتاح الزكيكــ

أستاذ مساعد بكلية التربية

جامعة المنصورة فرع دمياط

مجلة بحوث التربية النوعية - جامعة المنصورة

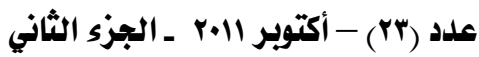




\title{
دور الإدارة الملدراسية في هماجهة التسرب الدراسي في المدارس المتوسطة بمحافظة الإصساء
}

\author{
إعداد \\ *** دممد محمود خطاب

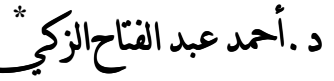 \\ : صaill
}

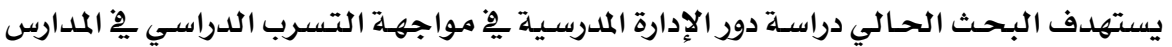

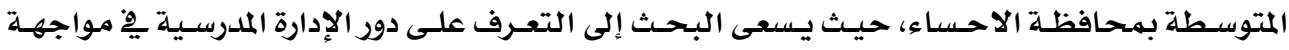

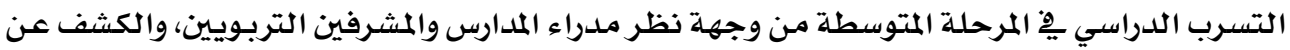

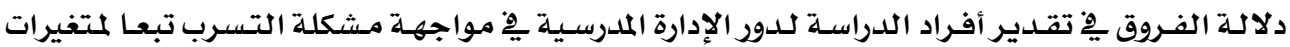

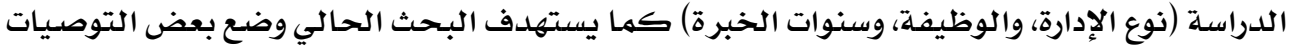
المقترحة ِِِ هذا المجال.

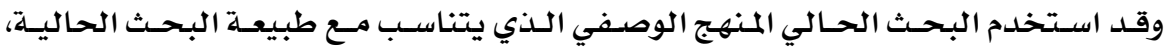
ولتحقيق أهداف البحث تم تصميم استبانة تستهدف التعرف على دور الإدارة المدرسية مـ خلال أربعـة

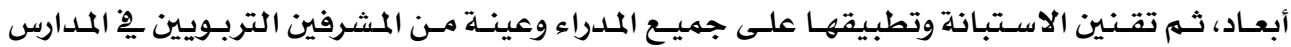

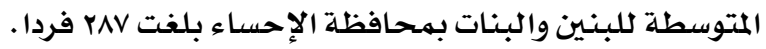

وقد توصل البحث إلى عدد مـن النتائج منهـا أن المتتوسـط العـام لدرجـة تقدير أفراد الدراسـة

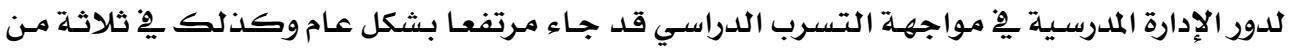

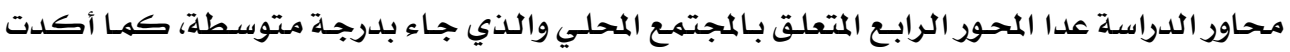

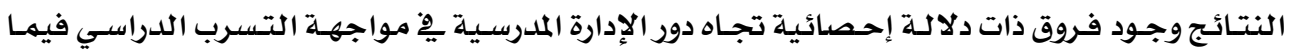

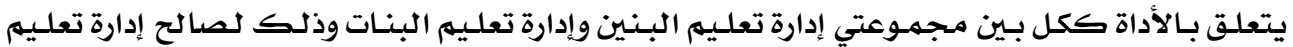

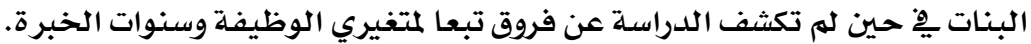

وخلصت الدراسـة الي تقديم بعض التوصيات التي تعهل على تفعيل دور الإدارة المدرسيـية يِ

$$
\text { مواجهة التسرب الدراسي. }
$$

* أستاذ مساعد بكلية التربية جامعة المنصورة فرع دمياط * * باحث تربـوي ، القاهرة 


\title{
Research summary
}

\section{THE ROLE OF SCHOOL MANAGEMENT IN FACING DROP-OUT IN THE INTERMEDIATE STAGE IN AL-AHSA GOVERNORATE}

\author{
Dr. Ahmed El-Zeki
}

Dr. Muhammad Khattab

The research aims at recognizing the role of school management in facing drop-out in the intermediate stage in Al-Ahsa governorate as a form of educational wastage, and recognizing the role of school management in this area as perceived by school managers and educational supervisors. It also aims at recognizing the significant differences in the opinions of study subjects about this role according to study variables. The research used the descriptive method and applied a questionnaire for recognizing school management role through four elements.

The results of this research indicate that the degree of the subjects' evaluation of the school management role in facing drop-out was high for the whole questionnaire and also for three parts whereas the degree was average for the fourth part (community).The results also indicate that there are statistically significant differences in the subjects' views between male and female sections of the education directorate (in favor of female section), whereas there are no statistically significant differences with regard to the variables of position and years of experience.

The research has concluded with some practical recommendations to activate the role of school management in facing drop-out. 


\title{
دور الإدارة المدربية في هواجهة التسرب الدراسي في المدارس المتوسطة بمحافظة الاصس
}

\author{
إعداد \\ *** دمحد محمود خطاب \\ د .أحمد عبد الفنّاحالزكيك
}

\section{مقدمة البحث:}

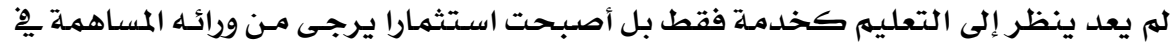

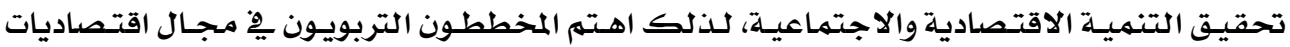

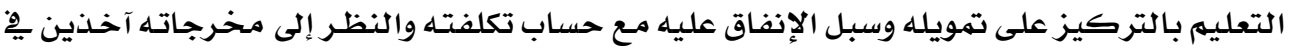

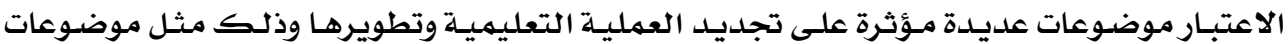

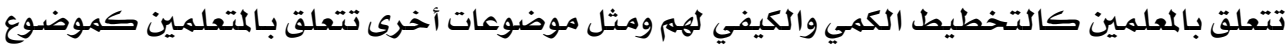

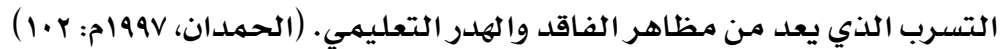

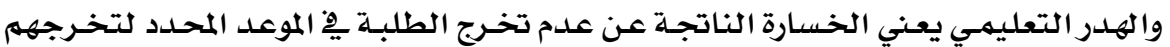

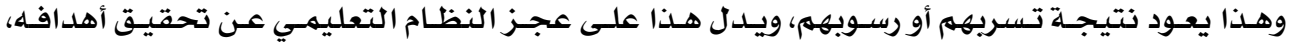

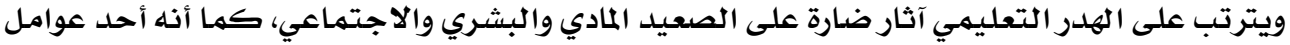

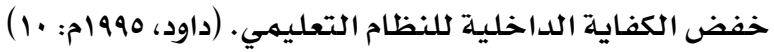
إذن فمفهوم الهدر التعليمي كمصطلح تريوي يشير إلي الرسوب والتسرب والتكلفـة الماليـة

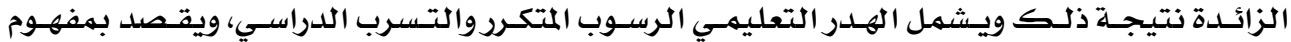

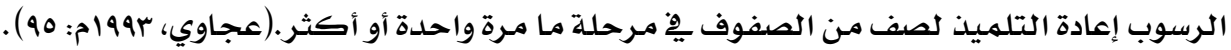
وتعد مشكلة التسرب الدراسي من أهم مظاهر الهلدر التعليمي والتي تعد مشكلة عالمية تعاني

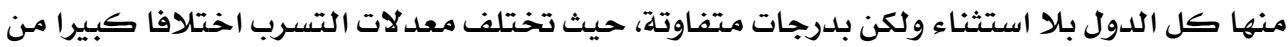

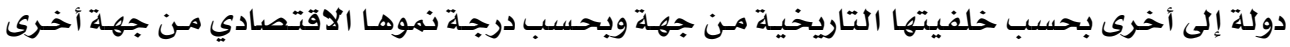

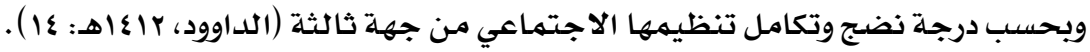

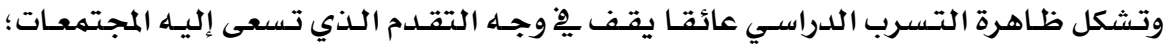

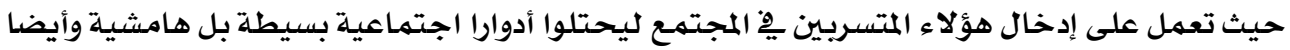

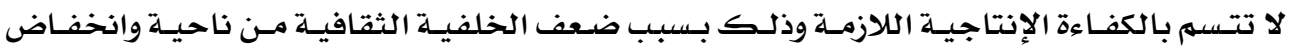

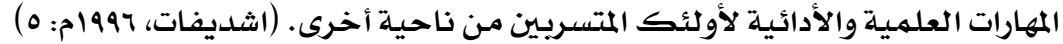




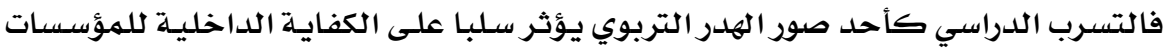

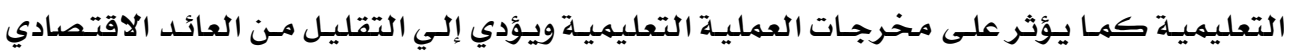

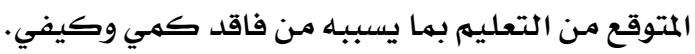

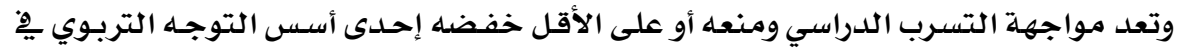

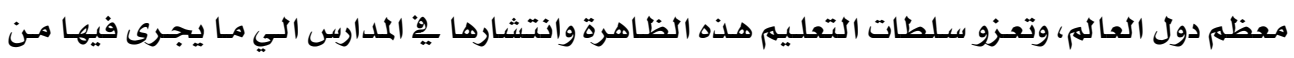

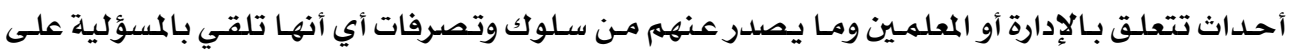

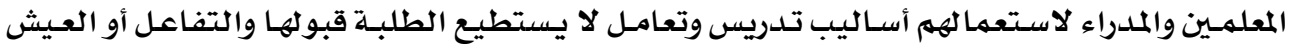

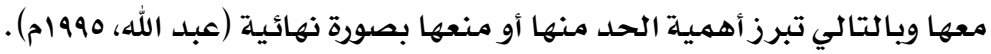

\section{هشكلة البحث والتساؤلات:}

يواجه التعليم مشكلات وصعوبات تعيق تقدمـه بالشكل المطلوب، ولعل مـن أخطر المشكلات

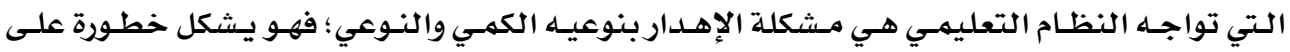

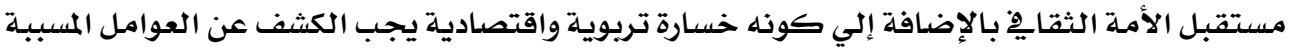

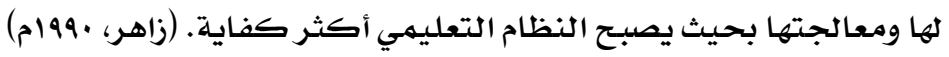

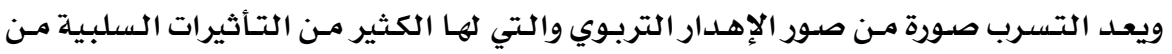

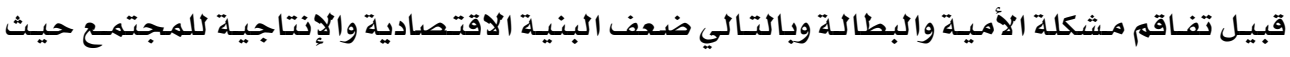

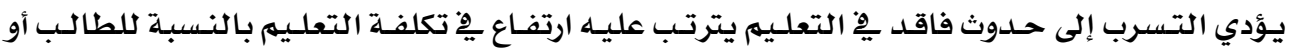

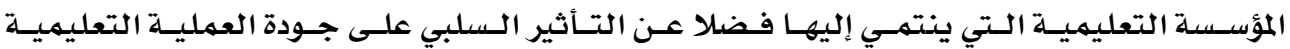
وكفاءتها.

وظاهرة التسرب رغم كونها آفة أكاديمية تريوية فإنها يف نهاية الأمـر لها أخطاروأضـرار في

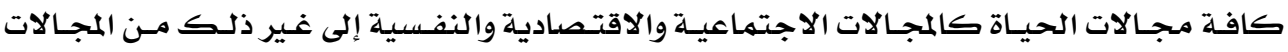

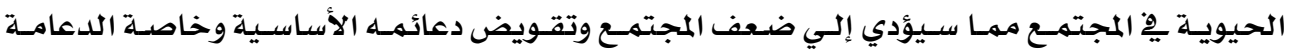

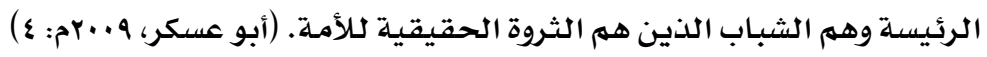

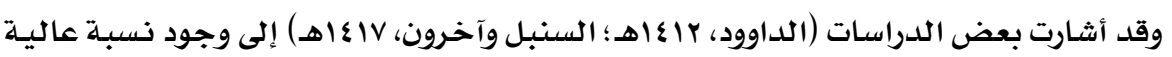

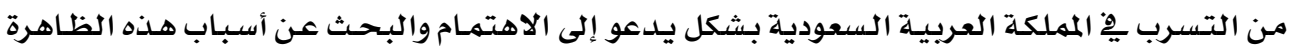

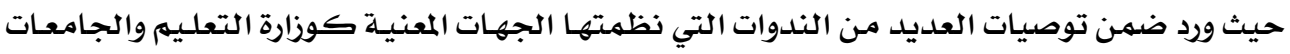

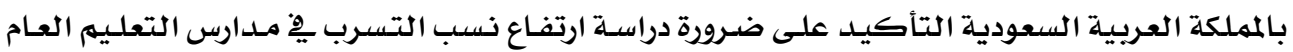
بالمملكة.

ومن هنا تبلورت مشكلة البحث والتي يمكن صياغتها ِِ2 السؤالين التاليين:

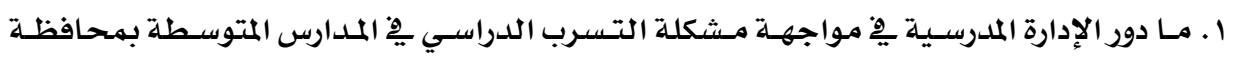

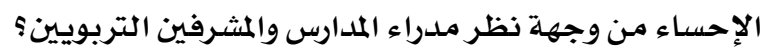




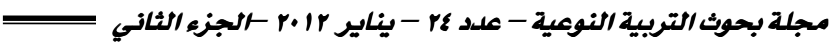

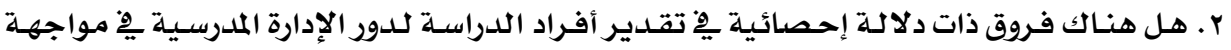

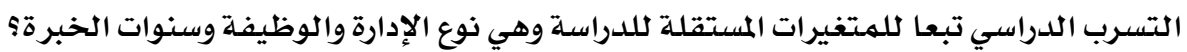

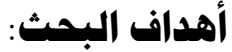

\section{يسعى البحث إلى تحقيق الأهداف التالية:}

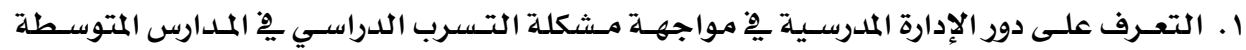

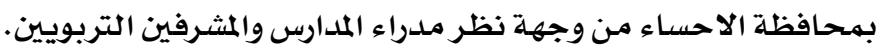

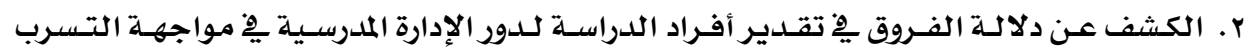

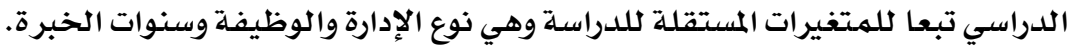

$$
\text { تنبع أهمية البحث الحالي مما يلي: }
$$

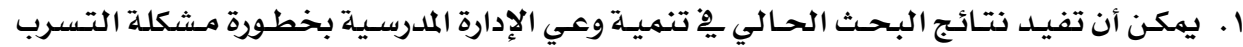

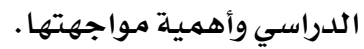

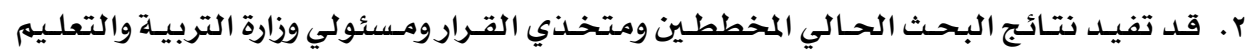

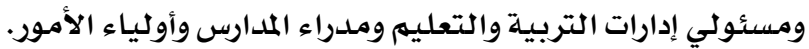

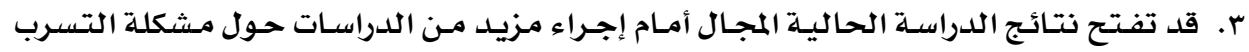

$$
\text { الدراسي للجنسين ِِّ مراحل دراسية أخرى. }
$$

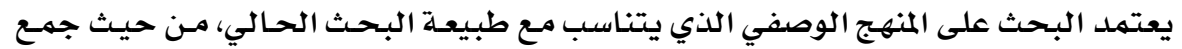

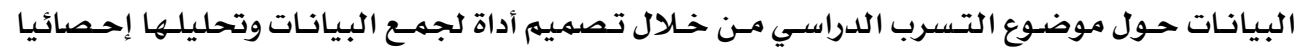
وتفسيرها ومناقشتها وصولا إلى تحقيق أهداف البـاف البحث.

\section{هدود البمث:}

• الحدود الموضوعية: اقتصرت الدراسـة على أربعة محاور تتمثل ِِّ دور الإدارة المدرسية فيما يتعلق

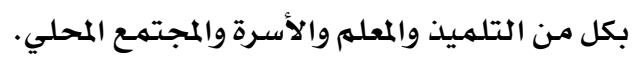

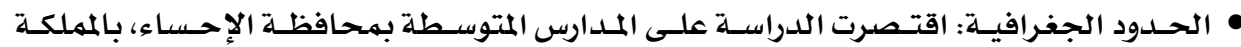

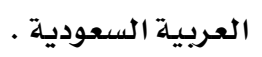

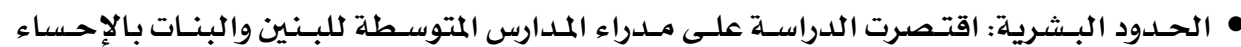

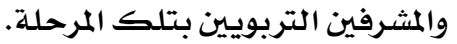

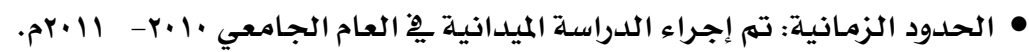

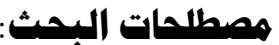

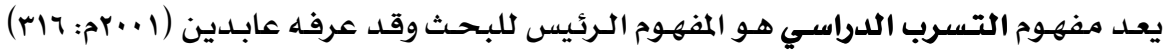

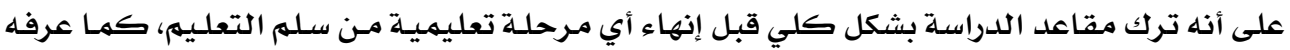




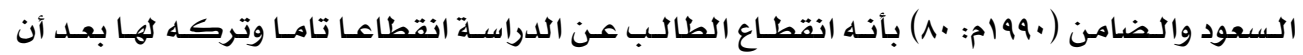

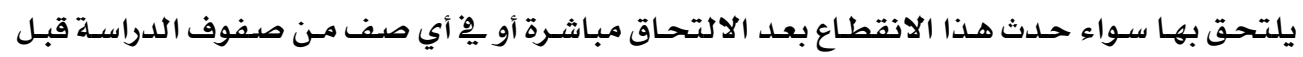

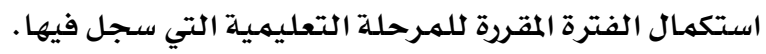

\section{دراسات سابقة:}

حظيت مشكلة التسرب الدراسي باهتمام الباحثين التربويـين منذ وقت طويل حيث تم تناول

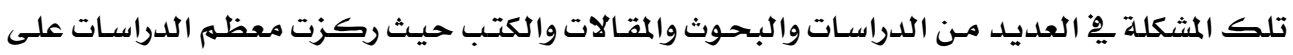

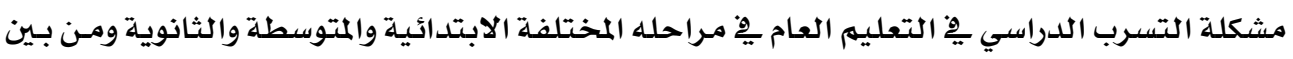

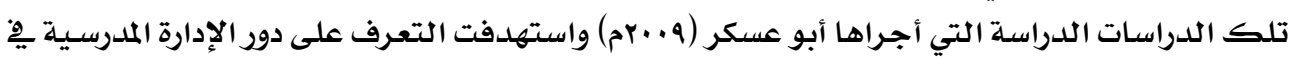

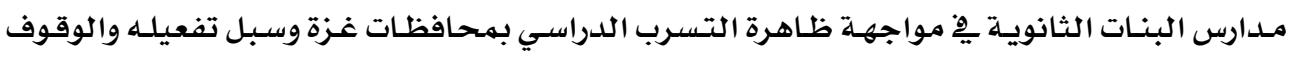

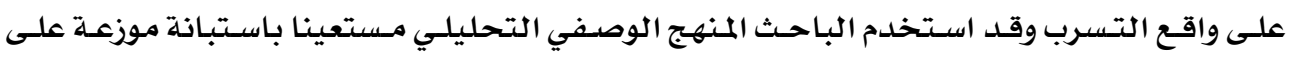

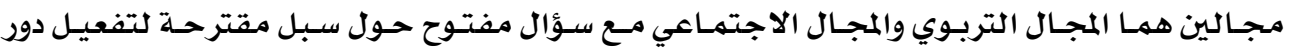

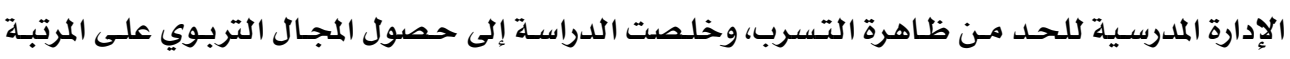

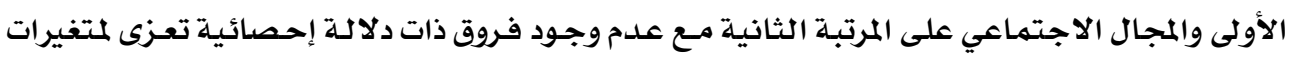

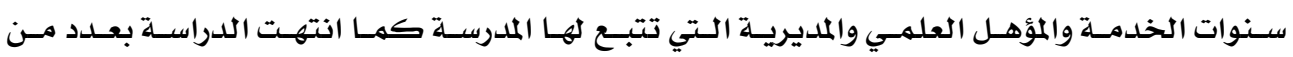

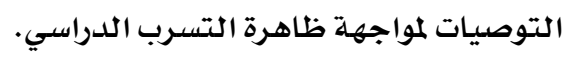

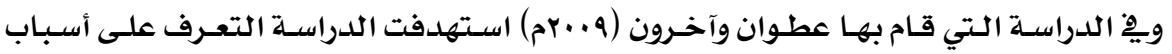

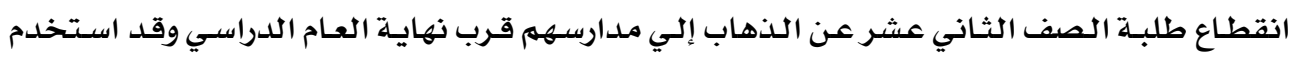

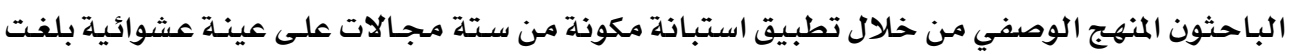

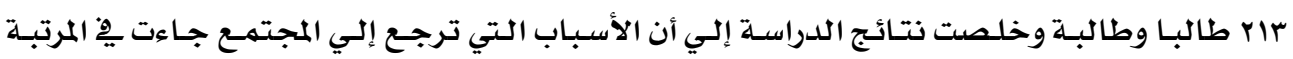

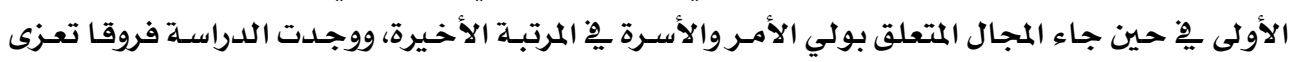

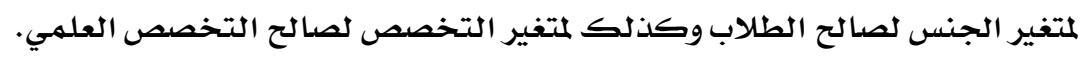

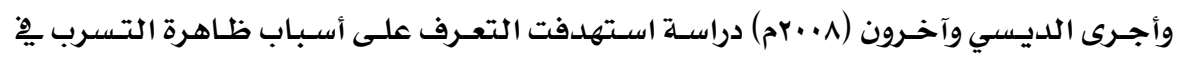

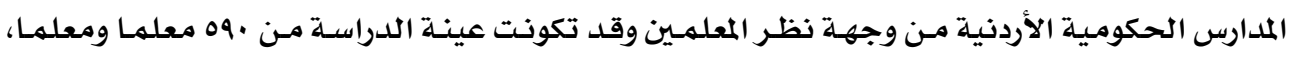

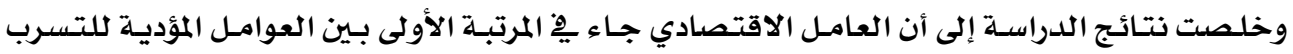

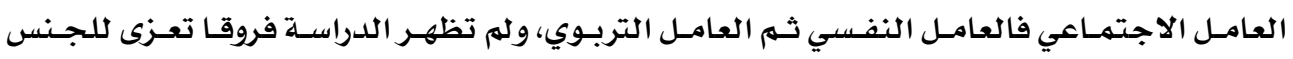

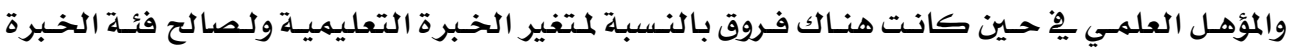

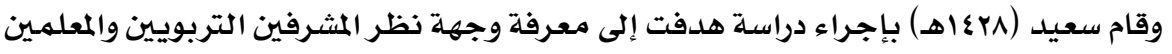

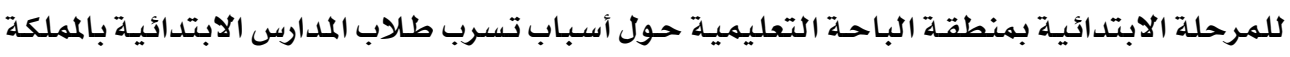

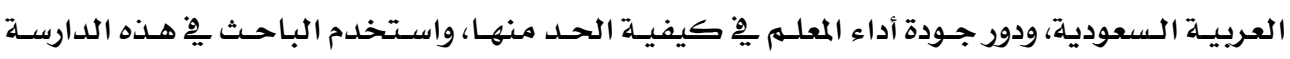

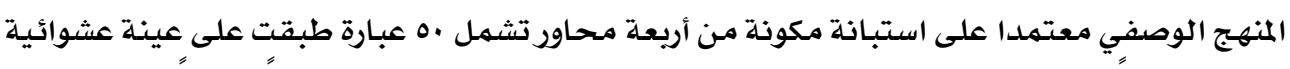

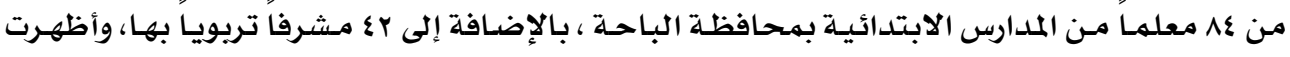




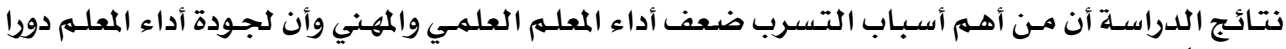

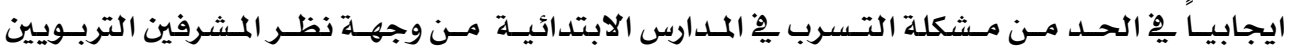
والمعلمـين.

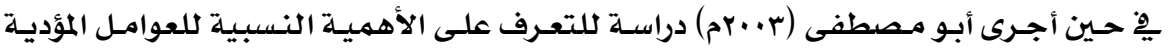

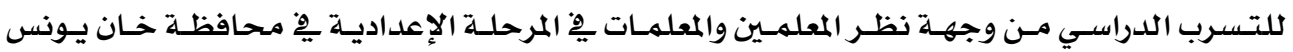

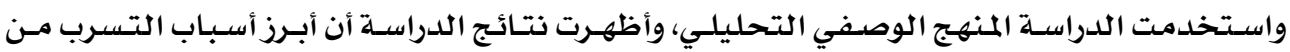

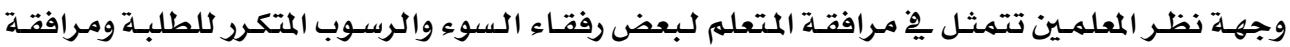

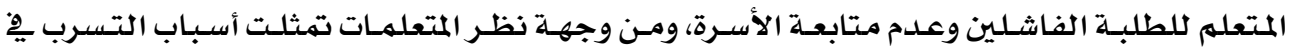

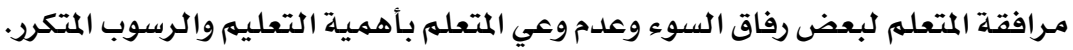

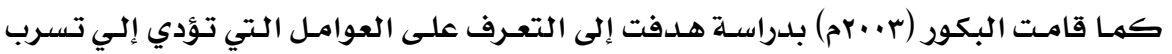

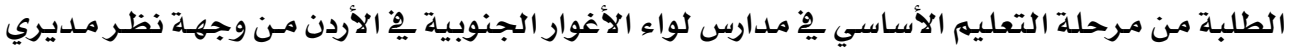

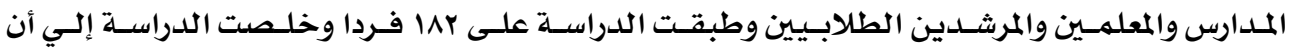

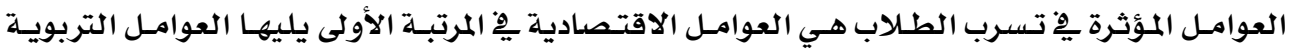

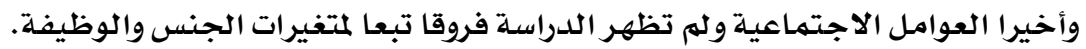

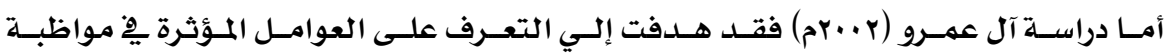

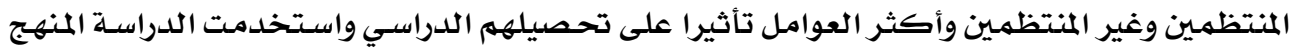

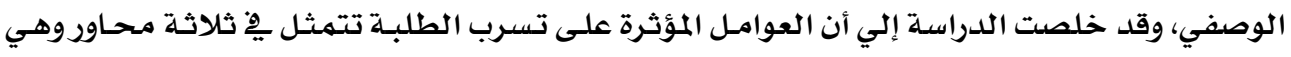

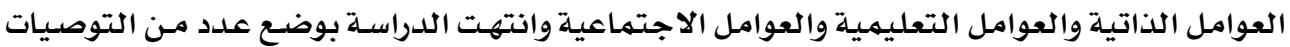

$$
\text { للحمد من تسرب الطلبـة. }
$$

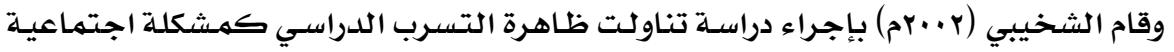

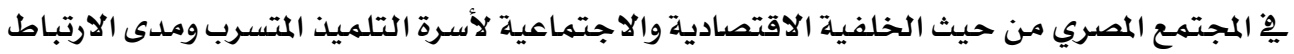

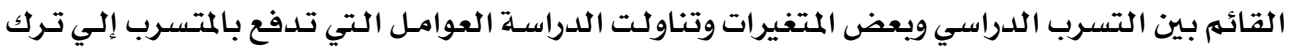

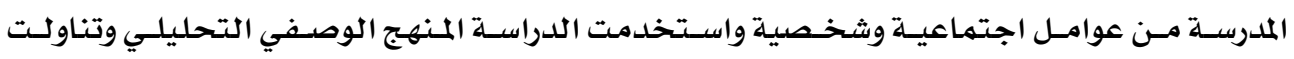

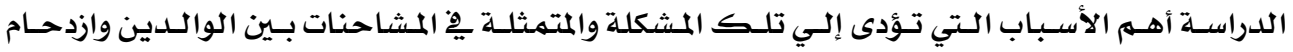

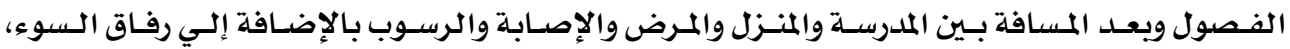

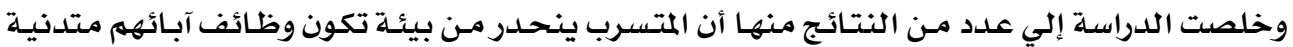

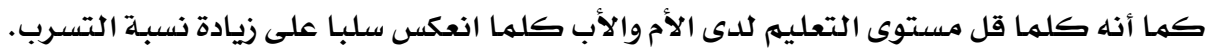

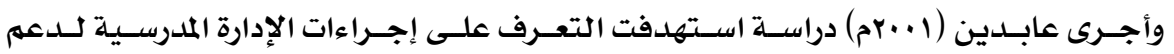

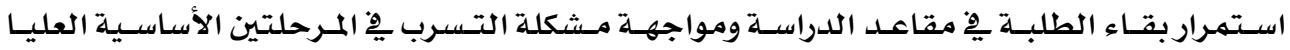

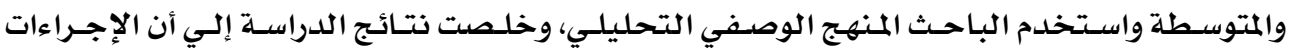

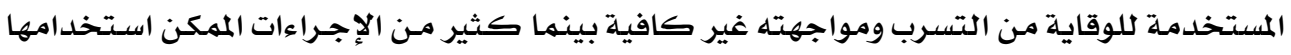




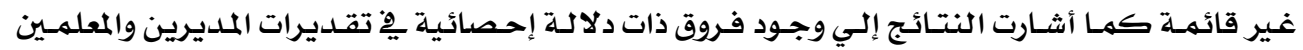

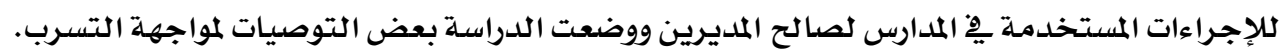

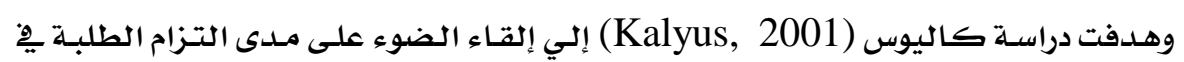

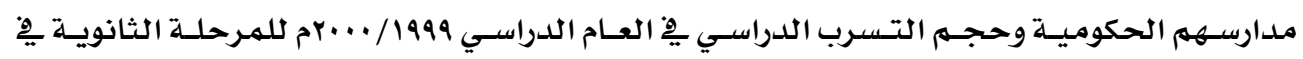

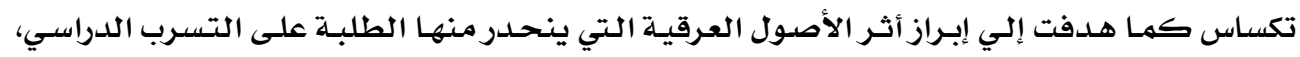

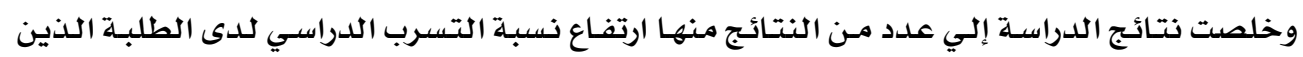

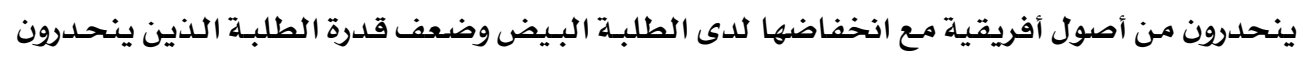

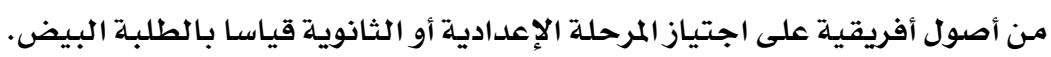

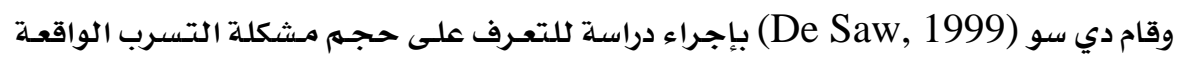

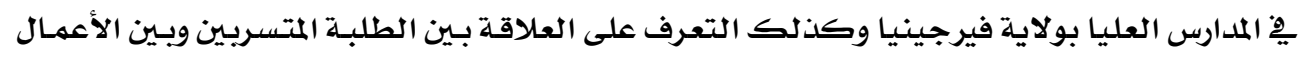

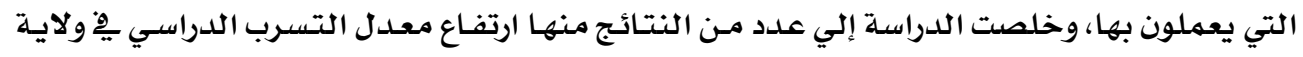

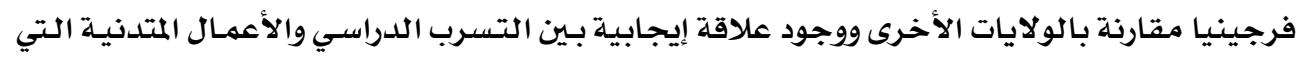

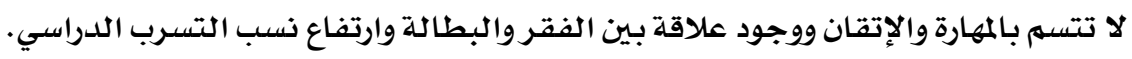

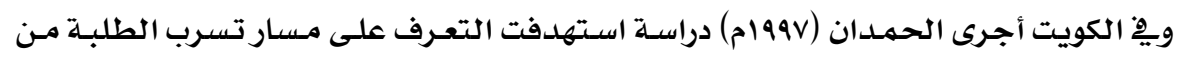

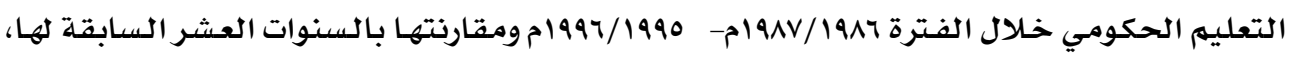

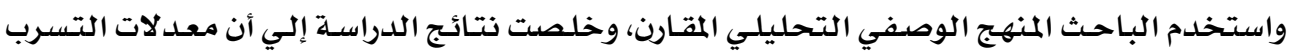

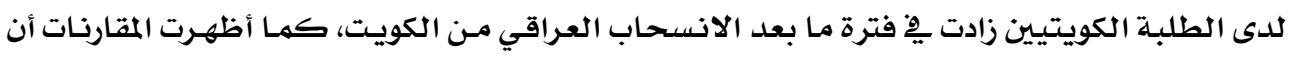

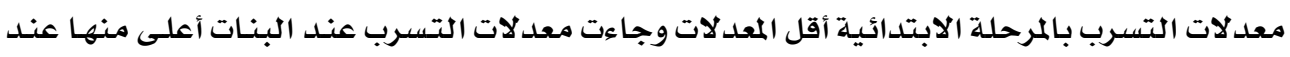

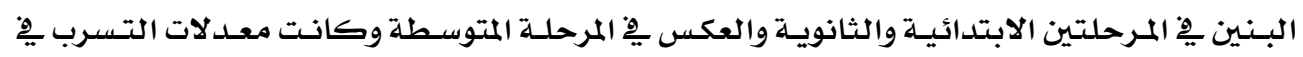

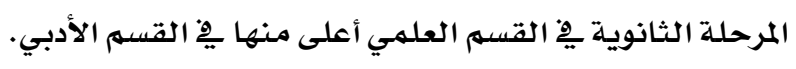

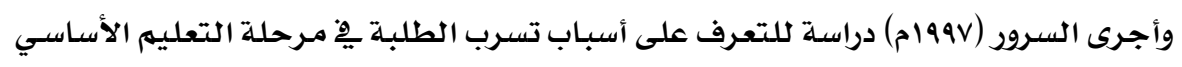

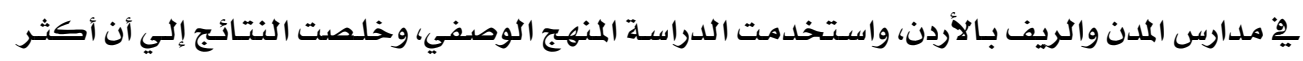

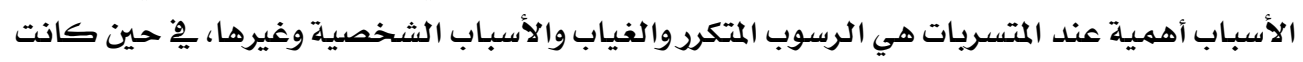

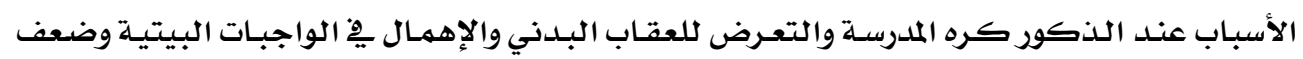

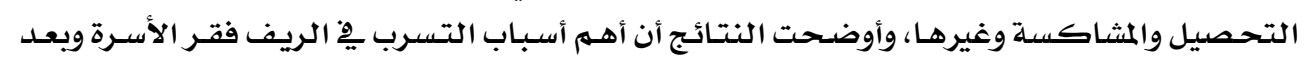

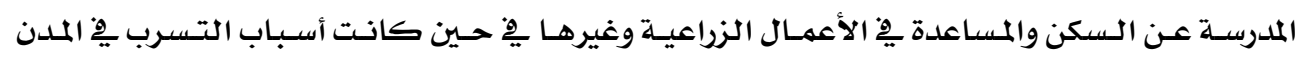

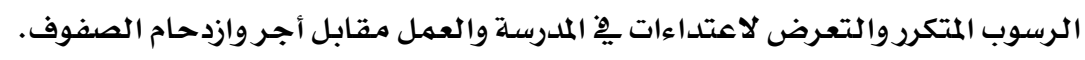

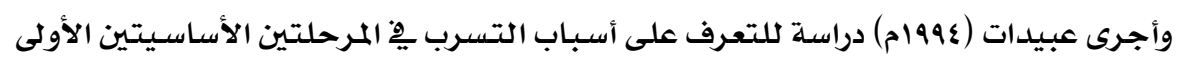

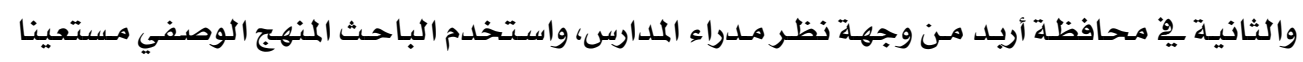

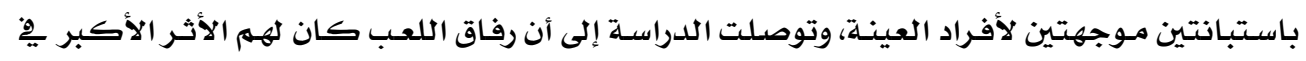

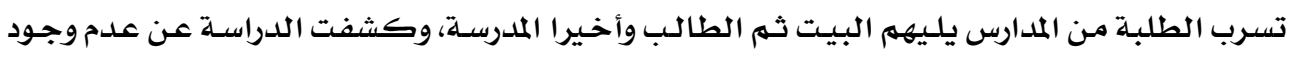




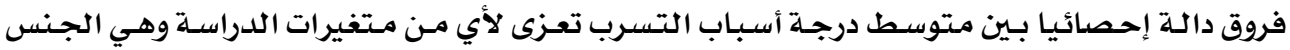

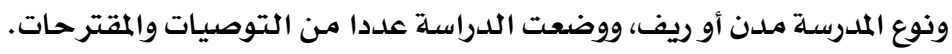

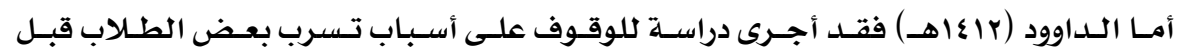

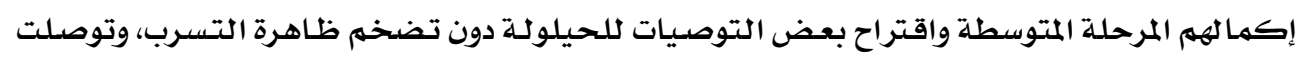

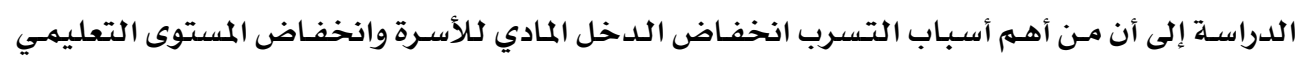

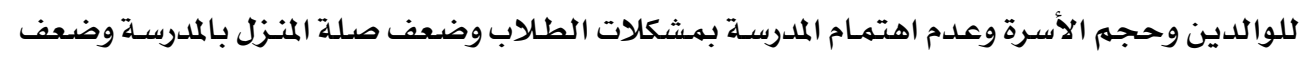

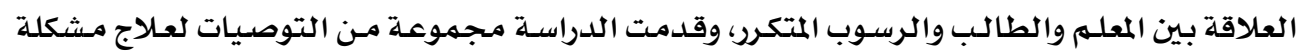
التسرب الدراسي بالمرحلة المتوسطة بالمملكة العربية السعودية.

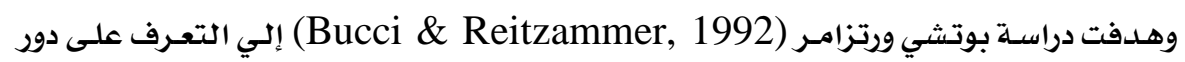

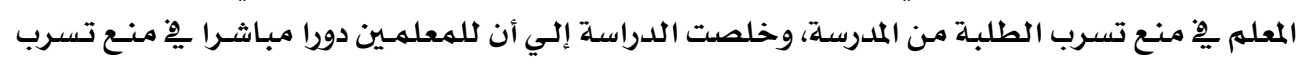

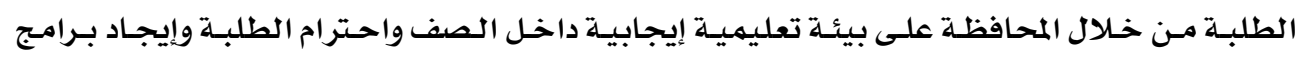

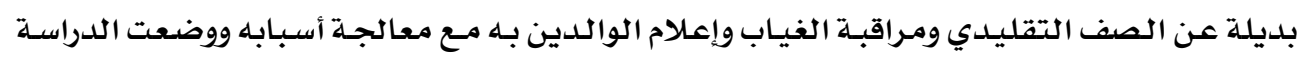

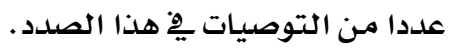

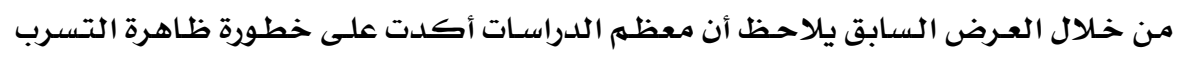

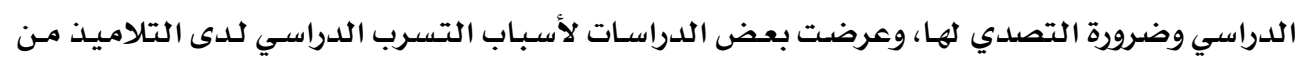

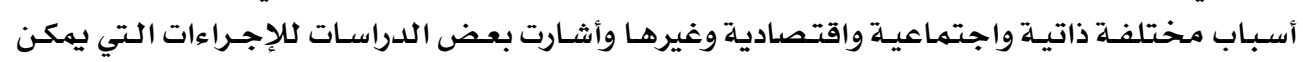

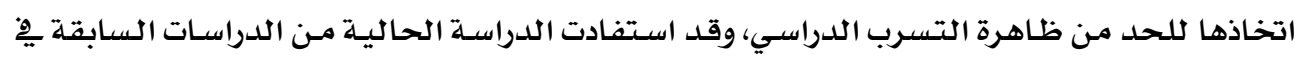

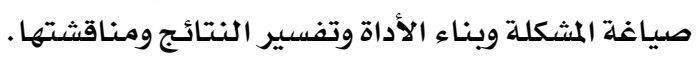

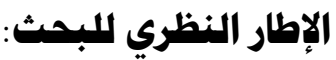

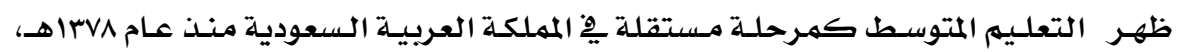

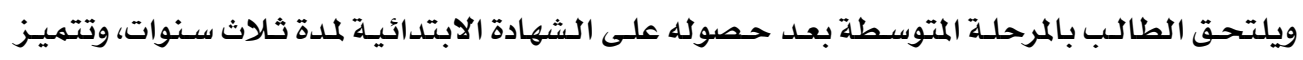

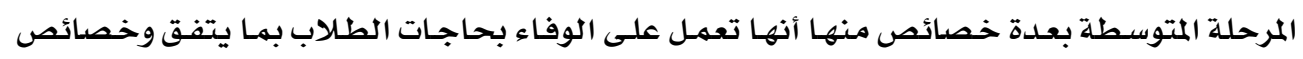

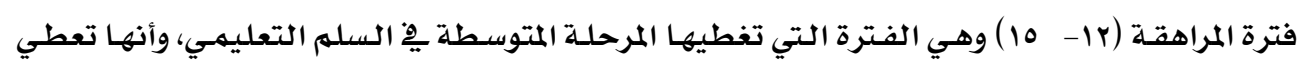

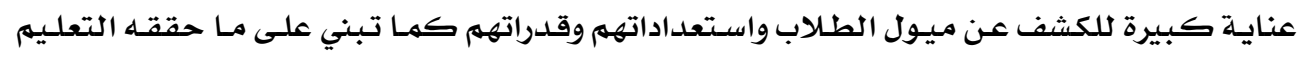

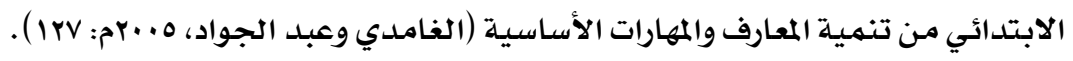

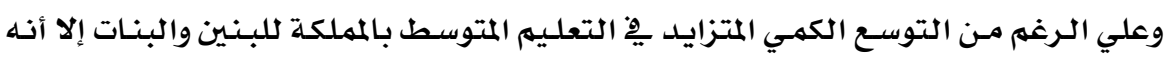

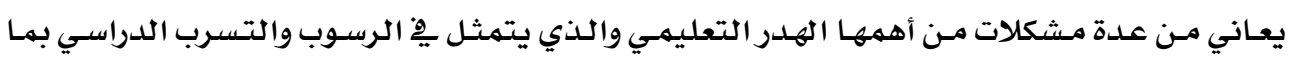

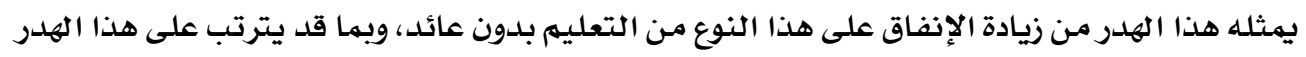

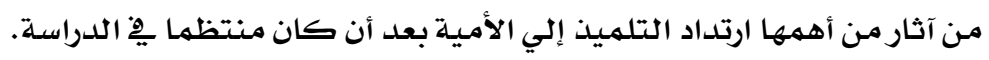

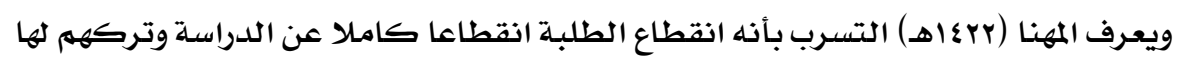

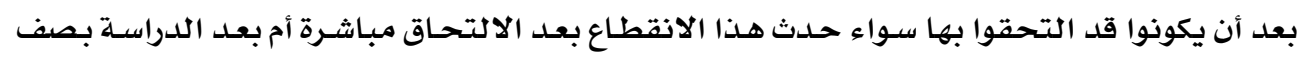

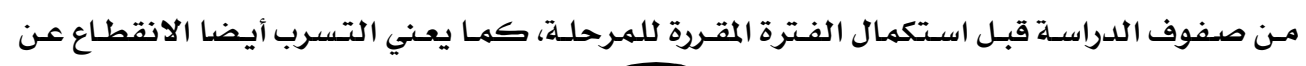




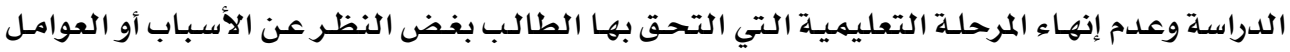

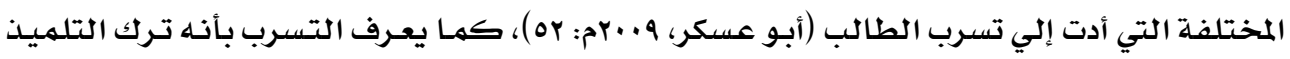

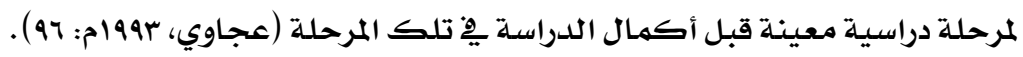

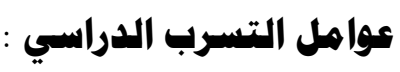

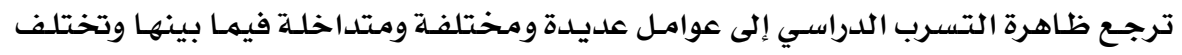

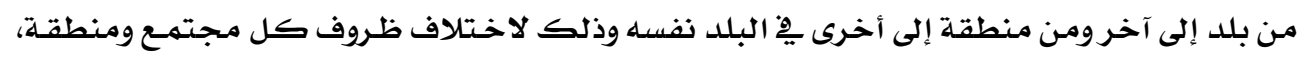

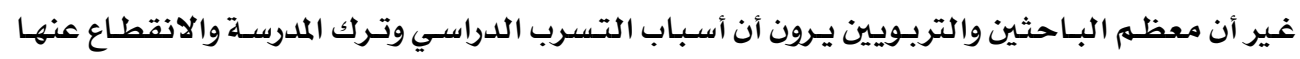

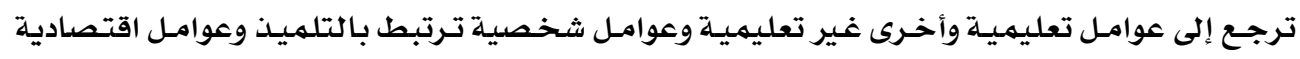

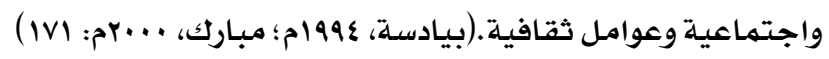

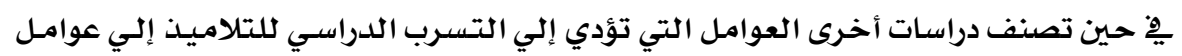

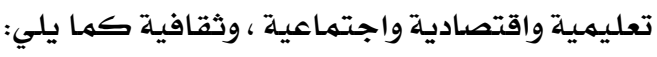

أ. عوامل تعليمية:

والتي ترتبط بعناصر العملية التعليميلة المختلفة وتشمل :

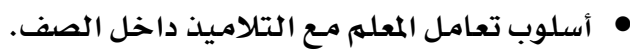

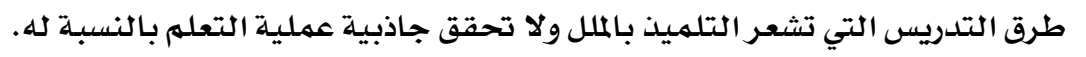

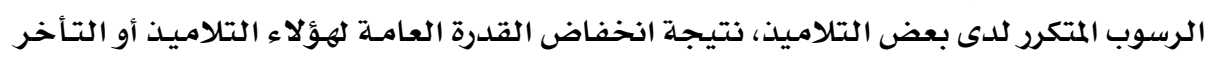
الدراسي يْ مواد دراسية معينة.

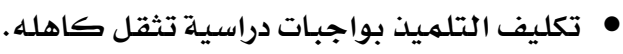

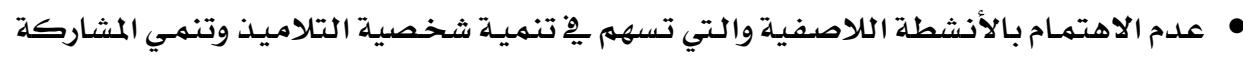
لديهم. أساليب التقييم التي تعتمد على قياس قدرة الطالب على الحفظ والاسترجاع.

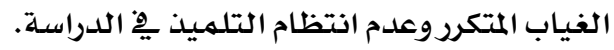

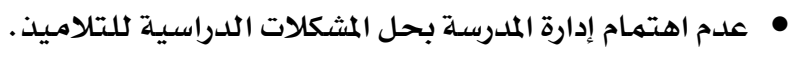

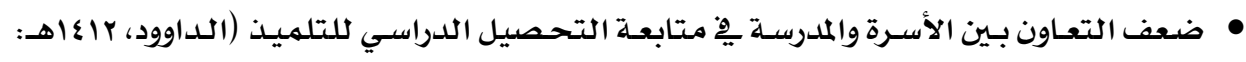

\section{بـ عوامل اجتماعية واقتصادية:}

توجـد مجموعـة مـن العوامـل الاجتمـاعيـة والاقتصـادية الـتي تقف وراء تسرب التلاميـذ مـن

$$
\text { المدرسسة من أهمها: }
$$

انعدام القيمـة الاجتماعية للتعليهم عند بعض الأسر مما يؤدي إلي إهمال الأسرة لمتابعة التقدم

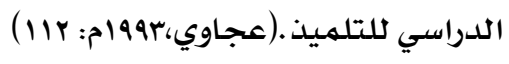


هالتفكـك الأسـري نتيـجـة الطلاق أو تعـلدد الزوجـات أو قسوة المعاملـة أو إهمـال متابعـة التلميـذ

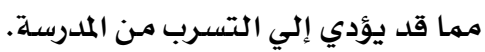
الآثار النفسية التي تترتب على المشكلات الاجتمـاعيـة للتلاميـذ بهـا لها مـن تأثير كبير على ملى

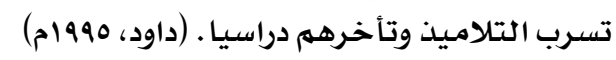
• انخفاض المستوي الاقتصادي والاجتماعي للأسـرة.

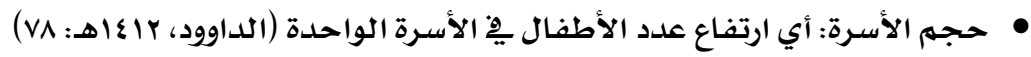

ج- عوامل ثقافية :

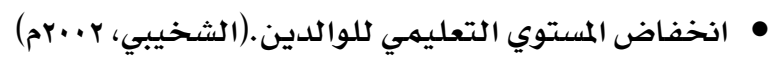

$$
\begin{aligned}
& \text { • عدم وعي الأسـرة بأهميـة التعليهم ومواصلـة التلميذيذ للدراسـة. } \\
& \text { عدم اهتتمام الأسـرة بهتابعة التحصيل الدراسي لـلأبنـاء. }
\end{aligned}
$$

\section{الآثار المترتبة على التسرب الدراسي :}

يهكن تصنيف الآثار التي تترتب على التسرب الدراسي إلي آثار تربوية واقتصسادية واجتماعية

$$
\text { ونفسيـة على النحو التالي: }
$$
أـــآثر تربوية :

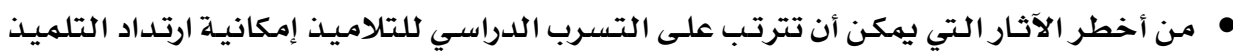

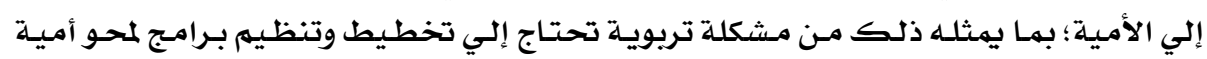

$$
\text { المتسربين. }
$$

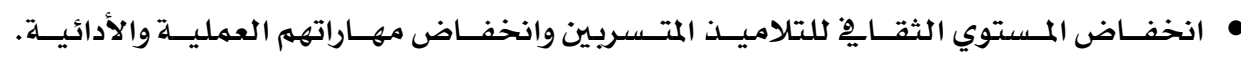

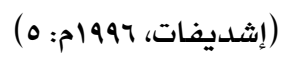

$$
\begin{aligned}
& \text { • عدم وعي التتلاميذ المتسربين بقضايا ومشكلات المجتمـع. }
\end{aligned}
$$

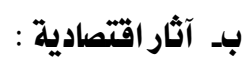

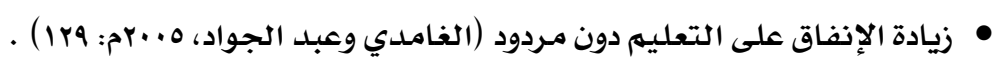

$$
\begin{aligned}
& \text { • ارتفاع تكلفة التلميذ بالمرحلة المتوسطة نتيجة التسـرب الدراسي. }
\end{aligned}
$$

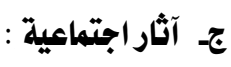

$$
\text { • قد يؤدي التسرب إلي الفراغ وانحراف بعض التلاميذ. }
$$

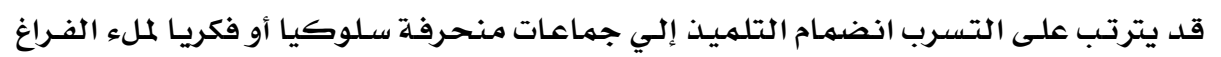

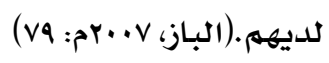

ه انتشار السلبيـة و الكلامبالاة بين التلاميذ المتسـريـين مها يؤدي إلي ضعف الانتماء لديهم.

دـ آثار ثفسية:

• قد يواجـه الطفل المتسـرب مشكلات يِّ التكيف مـع أقرانه المتعلمـين. 


\section{حبم هشكلة التسرب الدراسي :}

يعاني التعليم المتوسط بالمملكة العربية السعودية من الرسوب والتسرب الدراسي، ويِّ دراسـة

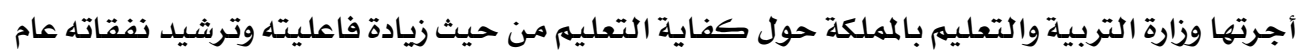

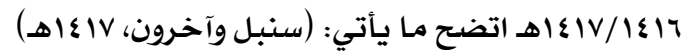

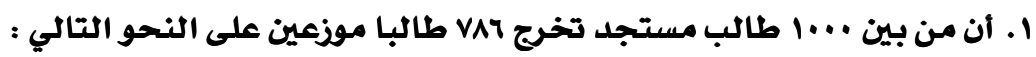

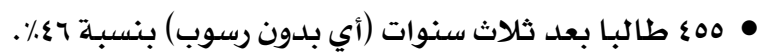

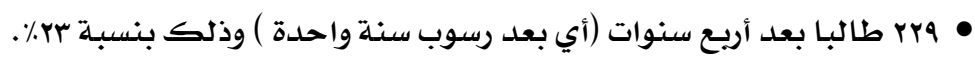

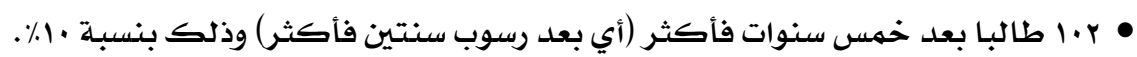

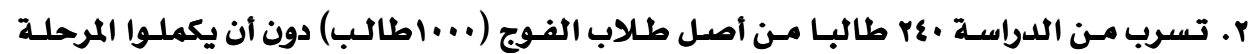

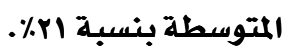

r. يقدر متوسط التكلفة لهذا الهدر بين طلاب المرحلة المتوسطة بنحو 7 •ع مليون ريال سنويا.

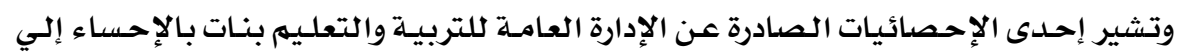

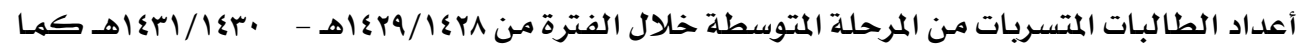
يتضح من الجدول التالي:

جدول [1]

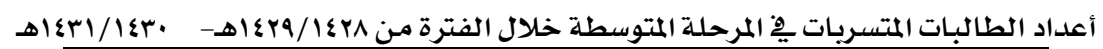

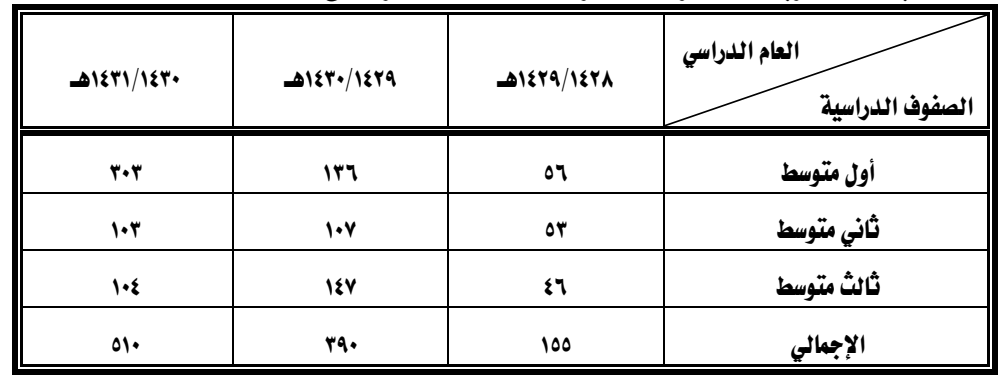

$$
\text { ويتضح من الجدول [1] ما يلي: }
$$

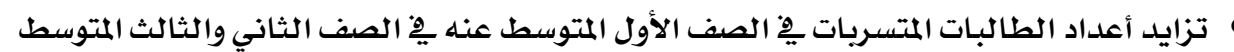

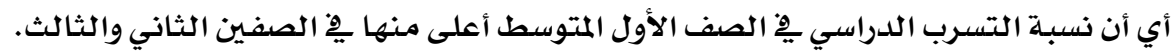

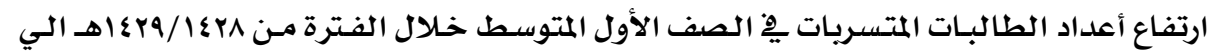

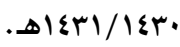

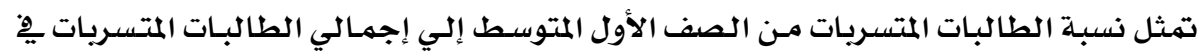

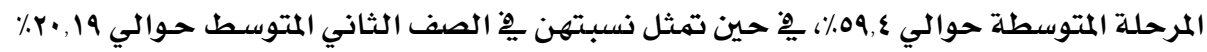

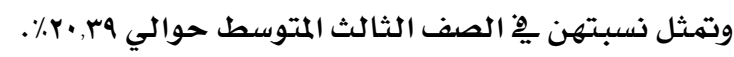


• وبـذلك يتضـح ارتفـاع نسب التسـرب الدراسـي لـدي طالبـات المرحلـة المتوسـطة بالإحسـاء مهـا يمثل نوعا من الهلدر التعليمي بالمرحلة المتوسطة.

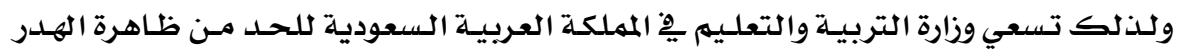

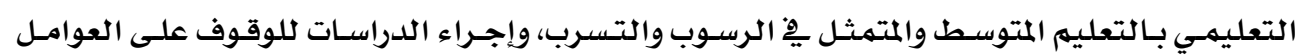
المؤديـة إليها بهدف القضاء عليها وتحسـين فاعلية التعليهم وكفاءته والاهتمام بتوجيه وإرثـاد الطلاب وتفعيل العلاقة بين الأسـرة والمدرسة وتطوير المناهـج والمقررات وتطوير نظمه تقـويم التلاميـذ (الغامـدي

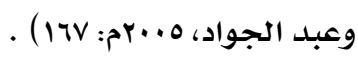

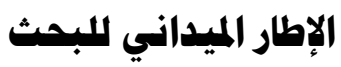
مجتمع البحث وعينته:

تألف مـجتهـع البحثث من جمـيع مدراء المدارس المتوسـطة للبـنـين والبنـات بهحافظلة الإحسـاء وجميـع المشرفين التربويين، وقد تم تطبيق الدراسة على جميـع مدراء المدارس المتوسطة للبنـين والبنـات

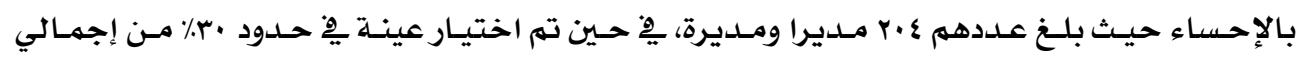

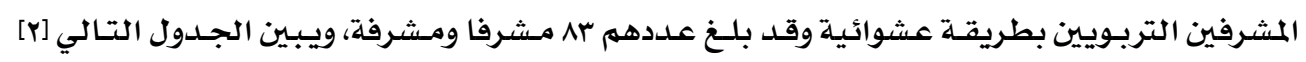
توزيع أفراد الدراسـة وفقا لمتغيراتها.

جدول [ب]

توزيـع أفراد الدراسـة وفقا للمتغيرات

\begin{tabular}{|c|c|c|c|}
\hline النسبـة المئويـة & العدد & أقسـام المتغير & المتغير \\
\hline rq, r & $1 \cdot \varepsilon$ & بنين & \multirow{2}{*}{ نوع الإدارة } \\
\hline (r,A & INr & بنات & \\
\hline VI,1 & $r \cdot \varepsilon$ & مدير & \multirow{2}{*}{ الوظيفة } \\
\hline 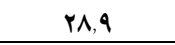 & $\Lambda$ & مشرف تربوي & \\
\hline$r \varepsilon$ & 79 & ه سنوات فأقل & \multirow{3}{*}{ الخبرة } \\
\hline ri, & q. & من 7 إلى · ا سنوات & \\
\hline$\varepsilon \leqslant, 7$ & IYA & أكثر من·1 سنوات & \\
\hline
\end{tabular}

تصميم الاستبانة :

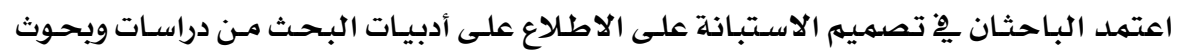

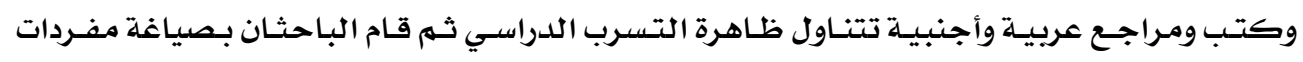

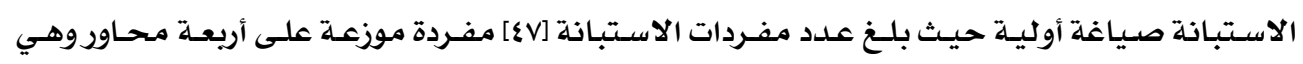

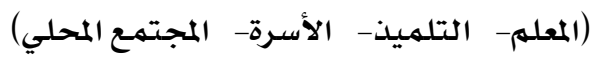

وقد صهمهت الاستبـانة على مقيـاس ليكرت الثلاثي (نعهم، إلى حـد مـا، لا ) حيـث أعطيـت نعهم

ثلاث درجات، وإلى حد ما درجتين، ولا درجـة واحدة. 


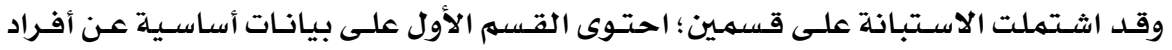

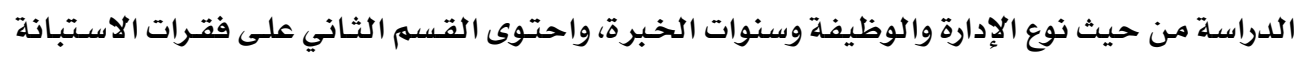

من خلال المحاور الأريعة.

تقنين الاستبانة:

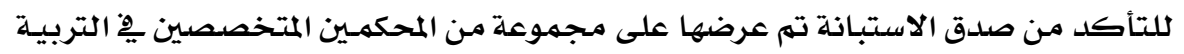

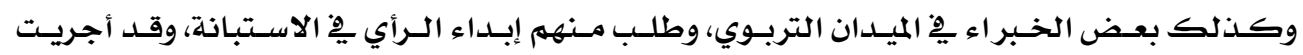

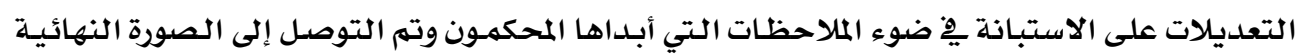

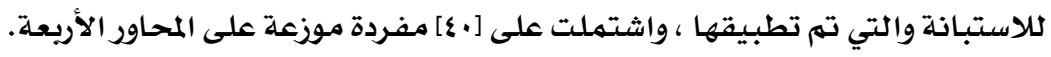

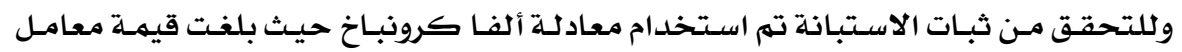

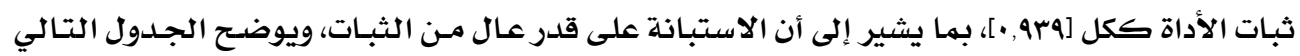

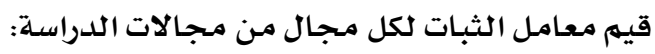

جدول [r] قيم معامل الثبات لكل محتور ولكلأداة ككل

\begin{tabular}{|c|c|c|c|}
\hline قيمـة معامل ارتباط ألفا & عدد الفقرات & المحور & r \\
\hline$\cdot, \wedge \cdot \wedge$ & 1. & دور الإدارة المدرسية فيما يتعلق بالتلميذ & 1 \\
\hline - var & 1. & دور الإدارة المدرسية فيما يتعلق بالمعلم & r \\
\hline$\cdot$ - Aro & 1. & دور الإدارة المدرسية فيما يتعلق بالتعاون مـع الأسـرة & $r$ \\
\hline., $9 \mu \mathrm{V}$ & 1. & دور الإدارة المدرسية فيما يتعلق بالمجتمـع المحلي & $\varepsilon$ \\
\hline$\cdot 949$ & $\varepsilon$. & الأداة ككل & \\
\hline
\end{tabular}

المعالجة الإحصائية:

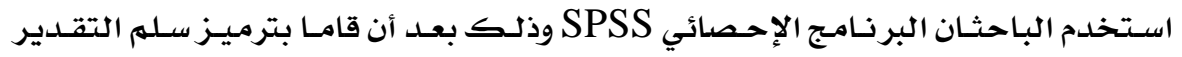

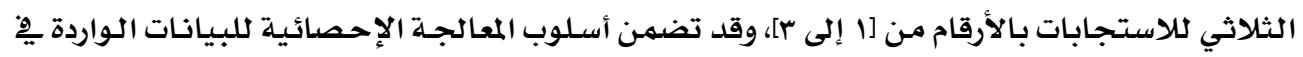

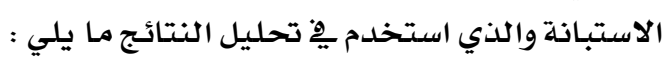

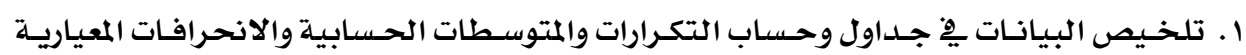

$$
\text { والنسب المئويـة. }
$$

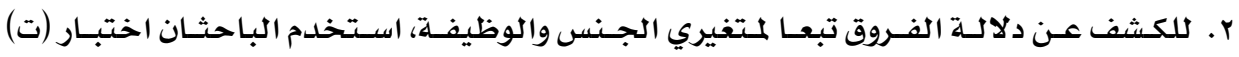

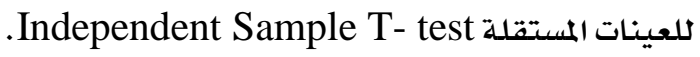
r. للكشف عن دلالة الفروق تبعا لمتغير سنوات الخبرة، استخدم الباحثان تحليل التباين الأحادي .One Way ANOVA 


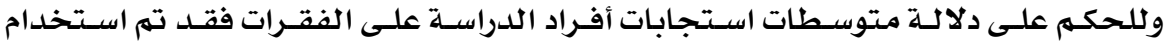

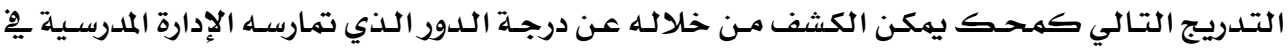

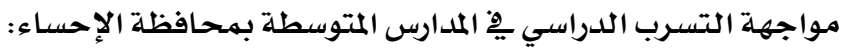

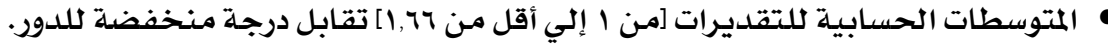

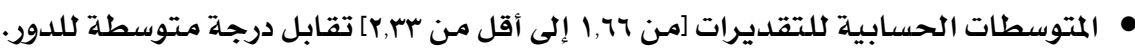

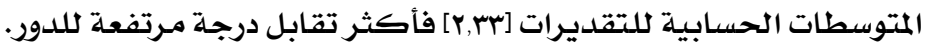

\section{نتائج البحث ومهناقشتها:}

لتفـسير نتـائج اسـتجابات أفـراد الدراسـة على الاسـتبـانة ومناقشتها قـام الباحثـان بتحليـل وتفسير النتائج تبعا لأسئلة الدراسلة كما يلي: نص السؤال الأول على:

"ما دور الإدارة المدرسية يِّ مواجهة مشكلة التسرب الدراسي يِّ المدارس المتوسطة بمحافظة الإحساء من وجهة نظر مدراء المدارس والمشرفين التربويين؟ ولإججابة عن هذا السؤال تم حساب التكرارات والنسب المئوية والمتوسط الحسابي والانحـراف

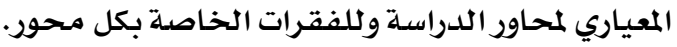
ويلاحظ من الجدول [§] أن المتوسط العـام لدرجـة تقدير أفراد الدراسـة لدور الإدارة المدرسيـية

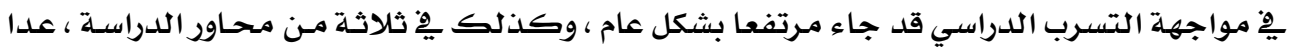

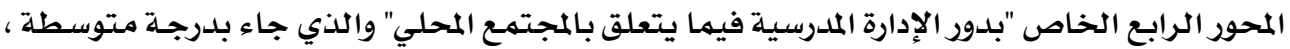

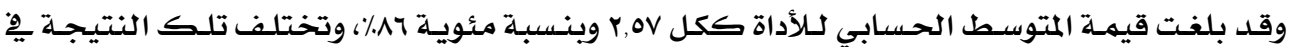

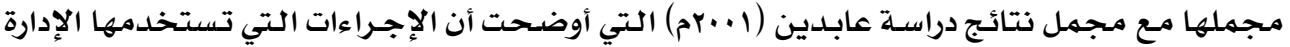

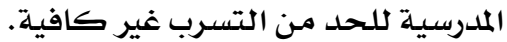

جدول [عا

نتائج التحليل الإحصائي لوجهة نظر أفراد الدراسـة ككل نحو دور الإدارة المدرسية يِّ مواجهة التسرب الدراسي

\begin{tabular}{|c|c|c|c|c|c|}
\hline الترتيب & درجة اللدور & الانحراف الممياري & المتوسط الحسابي & 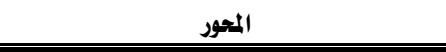 & ค \\
\hline r & مرتفعة & $r, 0 . r$ & r, $7 r$ & دور الإدارة المدرسية فيما يتعلق بالتلميذ & 1 \\
\hline 1 & 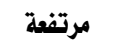 & $r, \eta 1 r$ & r, $\vee$ Q & دور الإدارة المدرسية فيما يتعلق بالمعلم & $r$ \\
\hline r & مرتفعة & $r, r \leqslant \wedge$ & r, Ir & دور الإدارة الملدرسية فيما يتعلق بالتعاون مع الأسرة & $r$ \\
\hline$\xi$ & متوسطة & 7, rro & $r, r_{\cdot}$ & دور الإدارة المدرسية فيما يتعلق بالمجتمع المحلي & $\varepsilon$ \\
\hline \multicolumn{2}{|c|}{ متوسطة } & Ir,qYq & r,or & \multicolumn{2}{|l|}{ الأداة ككل } \\
\hline
\end{tabular}

وقد احتل المحـور الخـاص "بـدور الإدارة الملدرسية فيمـا يتعلق بـالمعله" المرتبـة الأولى بهتوسط

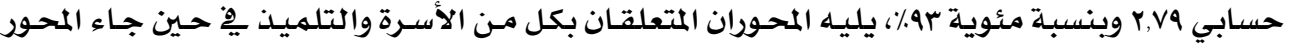

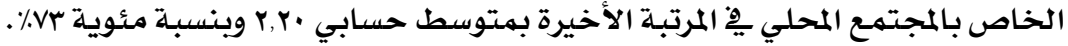




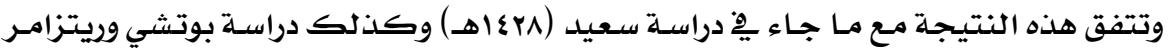

(Bucci \& Reitzammer, 1992)

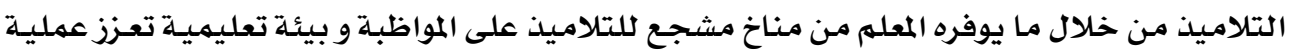

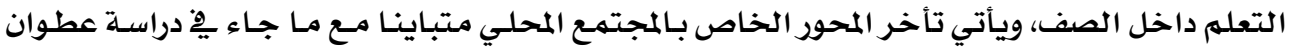

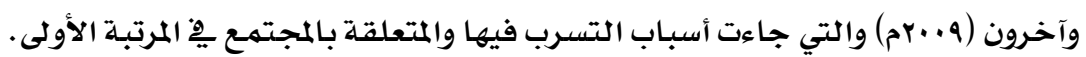
وفيما يلي مناقشة لكل محور من محاور الاستبانة على النحو التالي:

المحور الأول: دور الإدارة المدرسية فيما يتملق بالتلميذ:

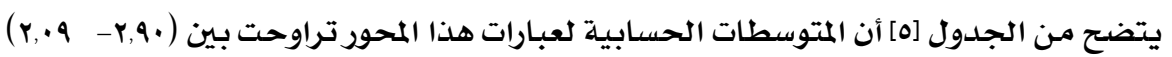

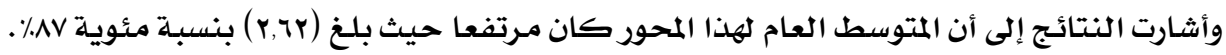
جدول [0]

نتائج التحليل الإحصائي لوجهة نظر أفراد الدراسـة بـالنسبة للمحور الأول (التلميذ)

\begin{tabular}{|c|c|c|c|c|c|}
\hline الترتيب & الدرجة & الانجراف & المتوسط & 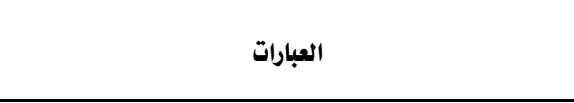 & P \\
\hline 1 & 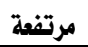 & •, ro9 & $r, q$. & تحفيز التلاميذ على الاتتظام في الحضور للمدرسة & $\xi$ \\
\hline r & 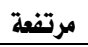 & $\cdot$, roq & $r, \wedge \varepsilon$ & تفعيل دور المرشد الطلابي في مساعدة التلاميذ ضعاف التحصيل & 0 \\
\hline r & 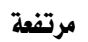 & $\cdot, r 90$ & $r, \wedge 1$ & الاهتمام بشكاوى ومقترحات التلاميذ بالمدرسة & 1 \\
\hline$\varepsilon$ & 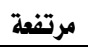 & $\cdot, 0 \cdot 1$ & r,vฯ & تعزيز مبدأ عدم التمييز في التعامل مع التلاميذ & 9 \\
\hline 0 & 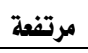 & •, ory & $r, 7 \Lambda$ & تنظيم مسابقات بين التلاميذ لتحقيق المنافسة الشريفة بينهم & $\wedge$ \\
\hline 7 & 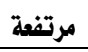 & $\cdot, 711$ & $r, \eta$ & الحرص على اكتشاف التلاميذ المعرضين للتسرب & r \\
\hline v & مرتفعة & $\cdot, 701$ & $r, 0 \varepsilon$ & الاهتمام بإشراك التلاميذ في التخطيط للأنشطة اللا صفية & $1 \cdot$ \\
\hline$\wedge$ & 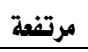 & $\cdot, 7 \wedge \varepsilon$ & r,o. & تنظيم برامج للحد من تسرب التلاميذ من المدرسة & $r$ \\
\hline 9 & 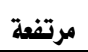 & $\cdot, 7 \leqslant \vee$ & r,§^ & تشجيع التلاميذ المتفوقين على مساعدة التلاميذ المتأخرين دراسيا & $\checkmark$ \\
\hline 1. & متوسطة & $\cdot, \Lambda \cdot Y$ & $r, \bullet q$ & توفير حصص إضافية للتلاميذ المتأخرين دراسيا & 1 \\
\hline \multicolumn{2}{|c|}{ 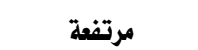 } & $r, 0 . r$ & $r, \pi r$ & المحور ككل & \\
\hline
\end{tabular}

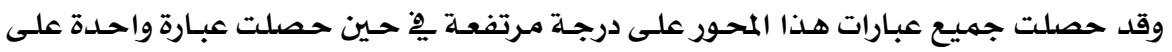

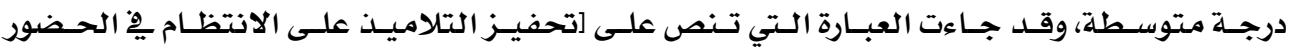

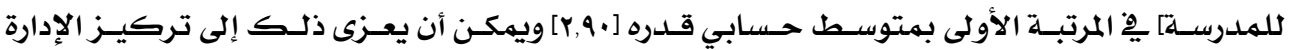

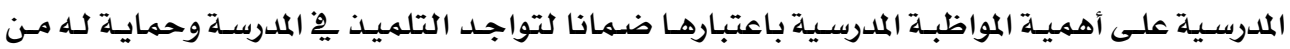

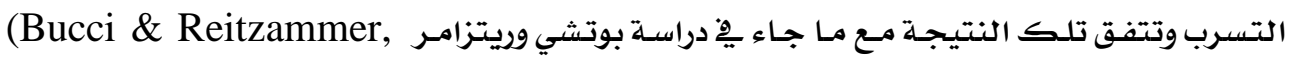

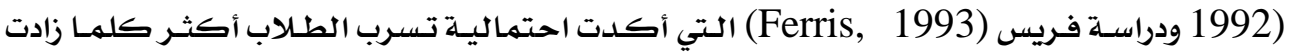

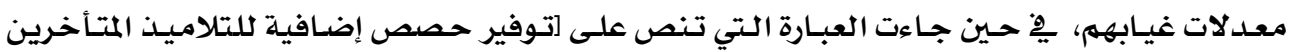




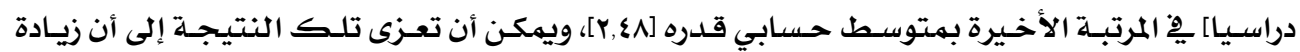

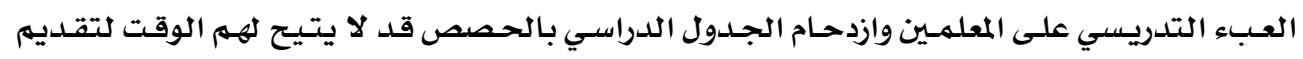

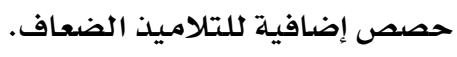

وقد حصلت العبارات ذات الأرقام [0-

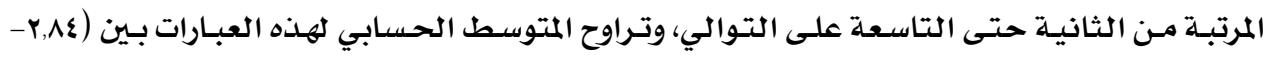

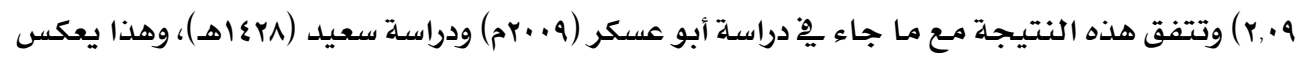

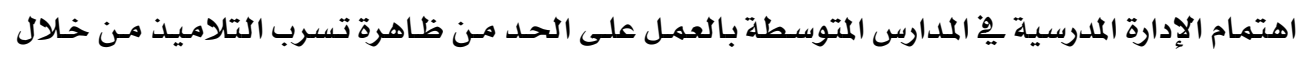

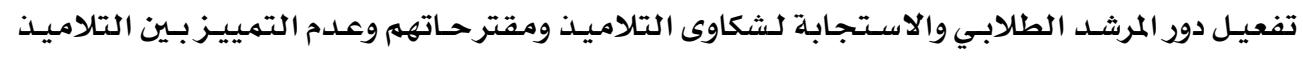

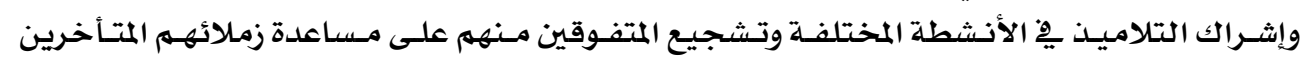

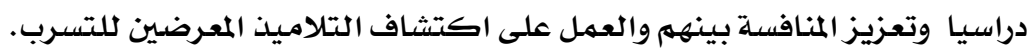

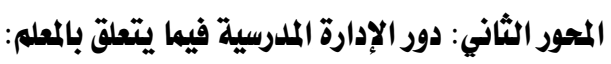

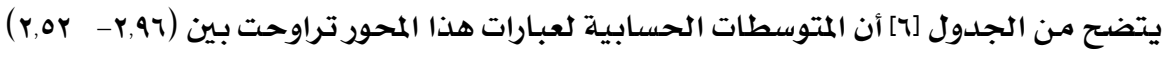

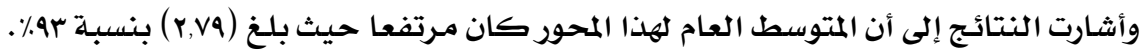

جدول [־]

نتائج التحليل الإحصائي لوجهة نظر أفراد الدراسة بالنسبة للمحور الثاني (المعلهم)

\begin{tabular}{|c|c|c|c|c|c|}
\hline الترتيب & لدرجة الدور & الالمعياري & المتوسط & 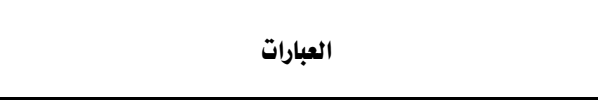 & P \\
\hline 1 & 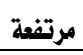 & •, $19 \mathrm{r}$ & $r, 97$ & حث المعلم على أن يكون قدوة حسنة لتلاميذ في كل سلوكياته & 1 \\
\hline r & 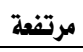 & •,req & ५, १६ & توعية المعلم بأهية حسن معاملة التلاميذ & r \\
\hline$r$ & 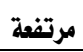 & •, & r,qr & توجيه المعلم إلى تجنب استخدام العقاب البدني & 7 \\
\hline$\varepsilon$ & 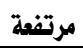 & • & $r, \wedge 9$ & أهية مراعاة المعلم للفروق الفردية بين التلاميذ & $r$ \\
\hline 0 & 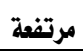 & •, r97 & $r, \wedge r$ & توجيه المعلم إلى تنويع طرق التدريس داخل الصف & $\varepsilon$ \\
\hline 7 & 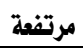 & •,\&Or & $r, \mathrm{rA}$ & حث المعلم على توفير فرص المشاركة والحوار للتلاميذ & $\checkmark$ \\
\hline$r$ & مرتفعة & , Orq & $r, \mathrm{r}$ & توجيه المعلم إلى عدم تكليف التلاميذ بواجبات مدرسية زائدة & 1. \\
\hline$\wedge$ & 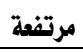 & , & $r, 7 \Lambda$ & حث المعلم على توظيف الأنشطة التربوية للحد من مشكلة التسرب & 0 \\
\hline 9 & 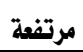 & 年, & $r, 71$ & تكريم المعلمين الذين يهتمون بحل مشكلات التلاميذ & 9 \\
\hline 1. & 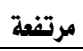 & $\cdot 719$ & r,or & تنمية مهارة المعلم من خلال تزويده بالخبرة لمواجهة تسرب التلاميذ & $\wedge$ \\
\hline \multicolumn{2}{|c|}{ 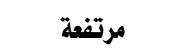 } & $r, \eta 1 r$ & $r, \mathrm{rq}$ & \multicolumn{2}{|l|}{ 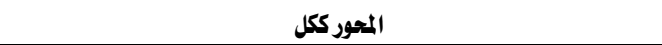 } \\
\hline
\end{tabular}

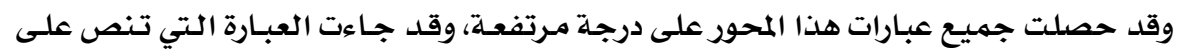

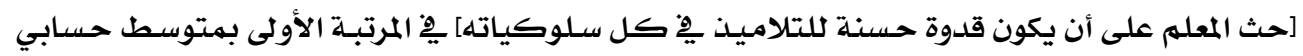

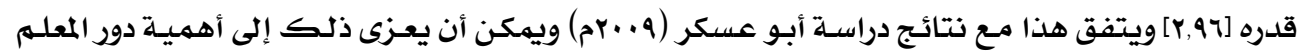




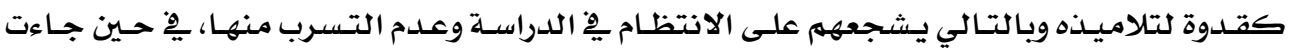

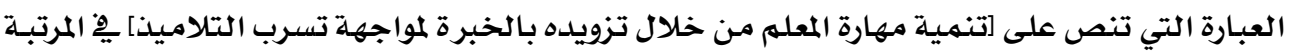

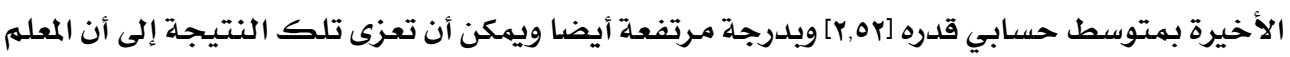

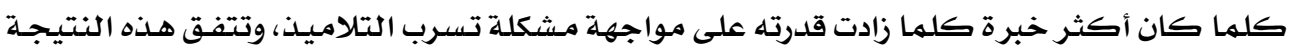

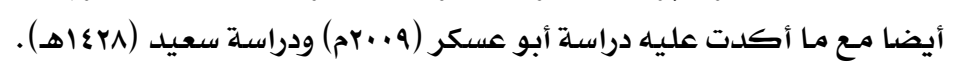

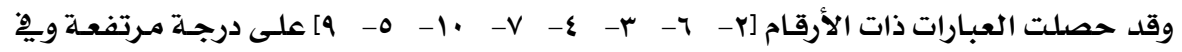

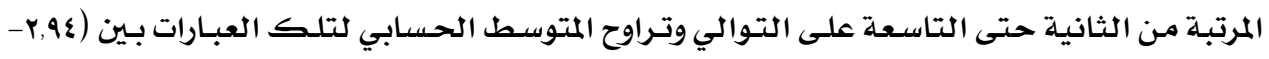

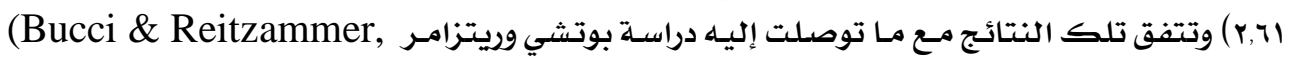

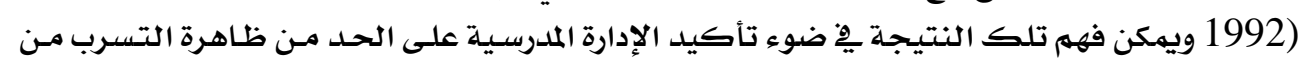

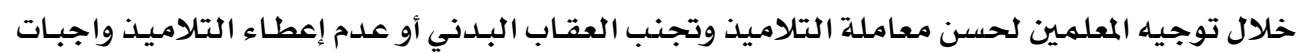

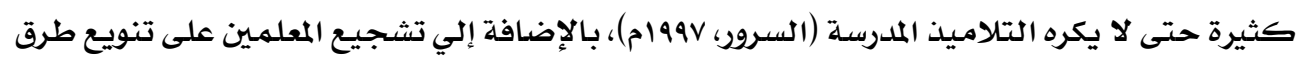

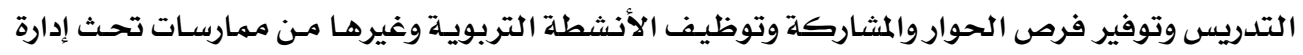

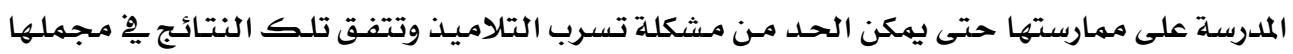

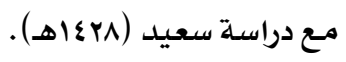

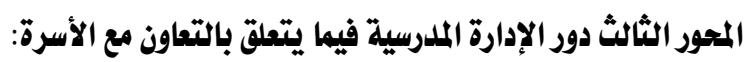

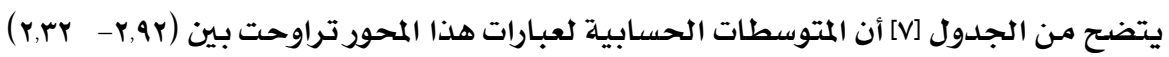

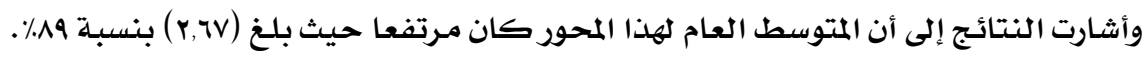

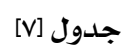

\begin{tabular}{|c|c|c|c|c|c|}
\hline الترتيب & لدرجة الدور & الالمعراف & الحتوسط & 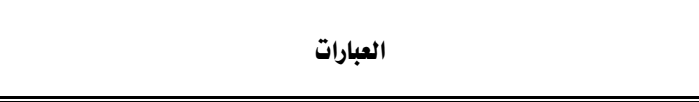 & r \\
\hline 1 & 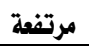 & $\cdot$, rav & r,qr & الاتصال المستمر بين الملدرسة وأولياء أمور التلاميذ متكرري الفياب & 0 \\
\hline$r$ & 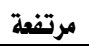 & •, rAV & r,q. & اطلاع أولياء الأمور على أداء التلاميذ من خلال تقارير دورية عن تحصيل أبنائهم & 1 \\
\hline$r$ & مرتفعة & $\cdot, \mathrm{rqA}$ & $r, \wedge 0$ & اهتمام المدرسة بمشاركة أولياء الأمور في مجالس الآباء & $\varepsilon$ \\
\hline$\varepsilon$ & مرتفعة & •,\$1A & $r, \wedge \varepsilon$ & حث الأسرة على المتابعة المنزلية لواجبات التلاميذ & $r$ \\
\hline 0 & مرتفعة & rilr & $r, \wedge \mathrm{r}$ & تشجيع أولياء الأمور على الحضور إلى المدرسة بصفة دورية لتقبعة تقدم أبنائهم & $r$ \\
\hline 1 & 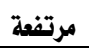 & •,oov & $r, r \cdot$ & مساعدة أولياء أمور التلاميذ الراسبين على تقدم أبنائهم & 9 \\
\hline$r$ & 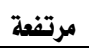 & $\cdot, 711$ & $r, \mathfrak{\varepsilon}$ & استخدام وسائل متنوعة لاستطلاع آراء أولياء الأمور حول العملية التعليمية & $\wedge$ \\
\hline$\wedge$ & 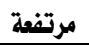 & •, ivo & $r, \xi T$ & تنظيم ندوات إرشادية لأولياء أمور التلاميذ التقأخرين دراسيا & $r$ \\
\hline 9 & 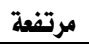 & $\cdot, 779$ & $r, \xi r$ & تزويد الأسر بما يساعدهم على توفير بيئة منزلية تعزز عملية التعلم & 1. \\
\hline 1. & 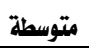 & $\cdot, \operatorname{rav}$ & $r, r r$ & إصلار نشرات توعوية لتوضيح آثار مشكلة التسرب & 7 \\
\hline \multicolumn{2}{|c|}{ مرتفعة } & $r, r \leqslant \wedge$ & $r, \mathrm{Tr}$ & \multicolumn{2}{|l|}{ المحور ككل } \\
\hline
\end{tabular}

نتائج التحليل الإحصائي لوجهة نظر أفراد الدراسة بالنسبة للمحور الثالث (الأسرة) 
وقد حصلت جميع عبارات هذا المحصور على درجـة مرتفعة عدا عبارة واحلدة حصلت على درجـة

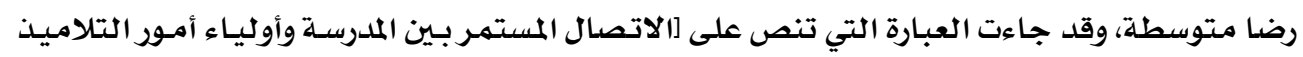

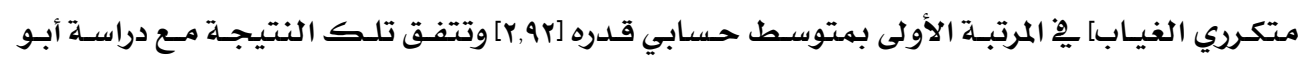

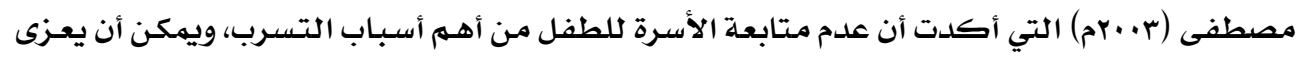

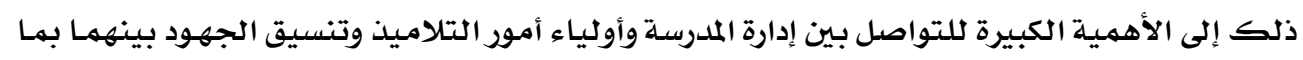

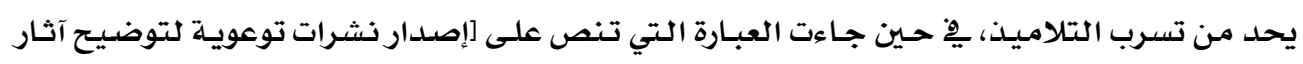

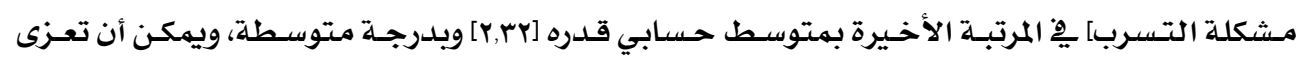

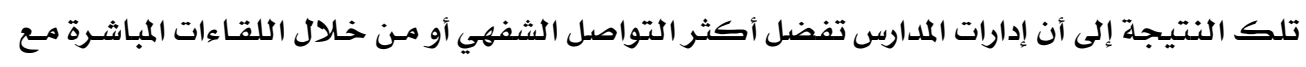

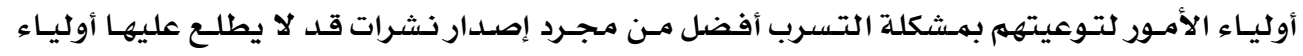

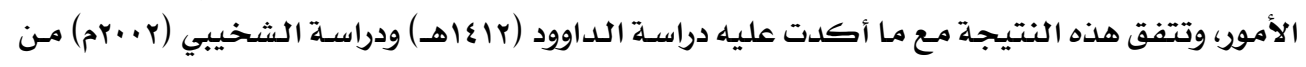

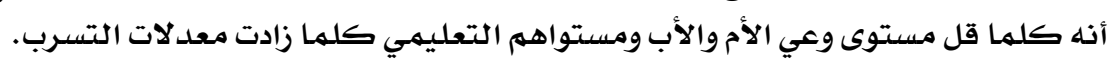

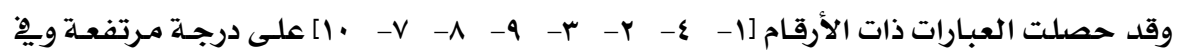

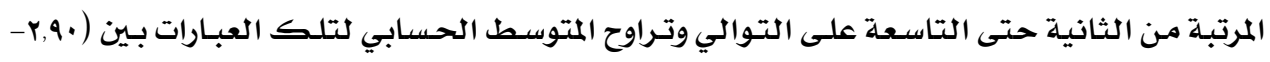

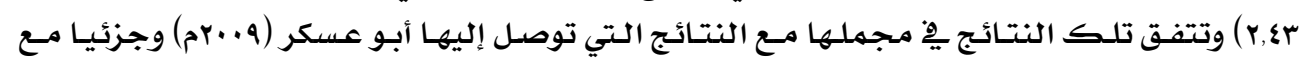

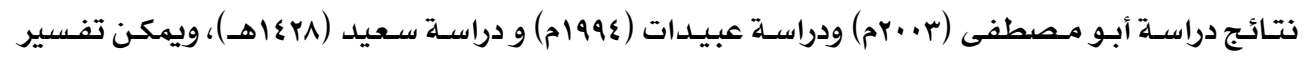

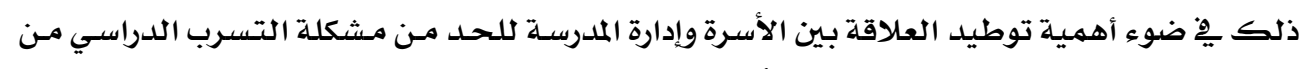

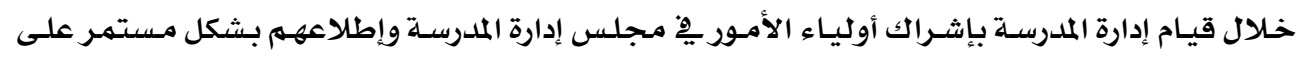

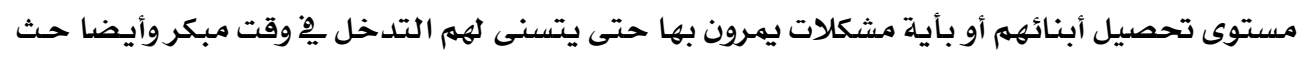

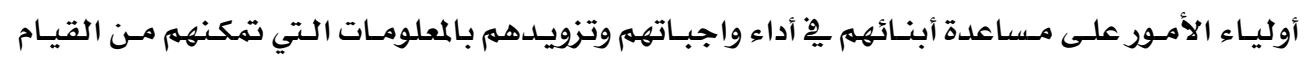

\section{المحور الرابع دور الإدارة الملدرسية فيما يتعلق بالمجتمع المحلي: بلمي}

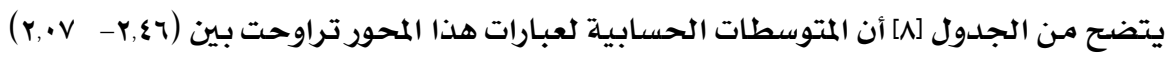

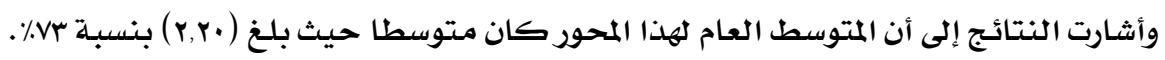




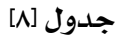

نتائج التحليل الإحصائي لوجهة نظر أفراد الدراسـة بـالنسبـة للهـحور الرابع (المجتمع المحلي)

\begin{tabular}{|c|c|c|c|c|c|}
\hline | الترتيب & | درجة الدور & الانحراف المياري & الحتوسط & 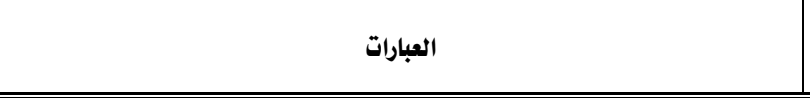 & a \\
\hline 1 & مرتفعة & $\cdot, 7 \wedge \wedge$ & $r, \$ 7$ & الاستفادة من برامج الجمعيات الأهلية في توعية التلاميذ بهخاطر التسرب & 9 \\
\hline r & 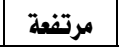 & $\cdot, \mathrm{v} / \varepsilon$ & r, ru & التواصل مع المجتمع المحلي لتفعيل مشاركة التلاميذ في خدمة المجتمع & $\varepsilon$ \\
\hline$r$ & 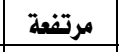 & $\cdot, \mathrm{VYA}$ & r,rr & تكامل دور المسجد مع المدرسة لحث التلاميذ على طلب العلم والتعليم المستمر & $r$ \\
\hline$\varepsilon$ & متوسطة & $\cdot$ • Alt & $r, 1 \Lambda$ & المشاركة في التوعية بما تتحمله ميزانية الدولة نتيجة التسرب الدراسي & 9 \\
\hline 0 & متوسطة & $\cdot, \mathrm{\vee 99}$ & $r, 17$ & المشاركة مع مؤسسات المجتمع المحلي في تقديم برامج توعوية لأولياء الأمور & $\wedge$ \\
\hline 1 & متوسطة & $\cdot, \wedge \cdot 0$ & $r, 10$ & لدعوة الشخصيات العامة في المجتمع للاستفادة من مقترحاتهم في علاج مشكلة التسرب الدراسي & 0 \\
\hline$\checkmark$ & متوسطة & $\cdot, 1 \cdot 0$ & $r, i r$ & التواصل مع وسائل الإعلام المختلفة للتوعية بحجم مشكلة التسرب اللدراسي وآثاره & 1. \\
\hline$\wedge$ & متوسطة & , $\vee \wedge A 9$ & r.l. & الاستفادة من المؤسسات الثقافية بالمجتمع في توعية التلاميذ بآثار التسرب الدراسي & $r$ \\
\hline 9 & متوسطة & •, ২q. & $r, \bullet \wedge$ & إيجاد مجالات للتعاون بين المدرسة والمجتمع المحلي & 1 \\
\hline 1. & متوسطة & $\cdot, \lambda \cdot \Lambda$ & $r, \cdot r$ & استثمار مؤسسات المجتمع المحلي لإشباع حاجات التلاميذ & $r$ \\
\hline \multicolumn{2}{|c|}{ 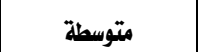 } & 7, rro & $r, r$. & \multicolumn{2}{|l|}{ المحور ككل } \\
\hline
\end{tabular}

وقد حصلت ثلاث عبارات يِّ هذا المحور على درجـة مـرتفعة يِ حسين حصلت سبـع عبـارات على

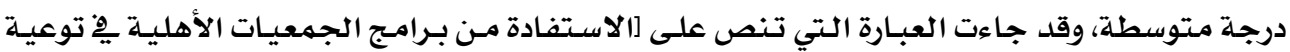

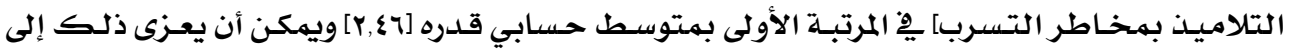

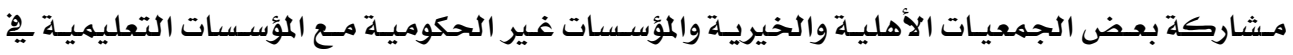
إطـلاق بعض المبـادرات الـتي تهـلـف إلـي الحسد مـن ظـاهرة التـسـرب الدراسـي، وبالتـالي تسـتطيع إدارة

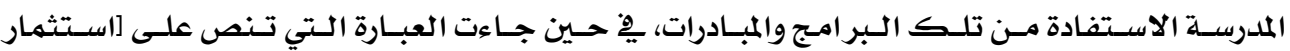

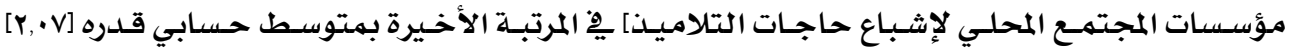

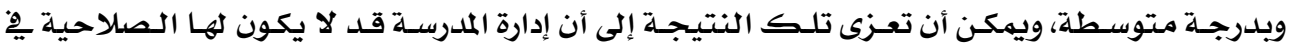

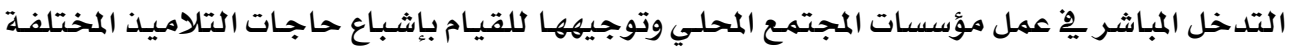
بها يمكنهم من تجنب التسرب الدراسي.

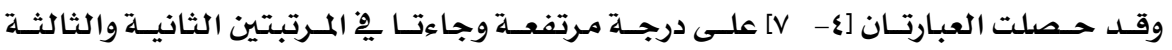

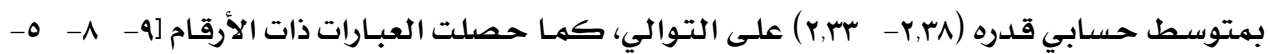

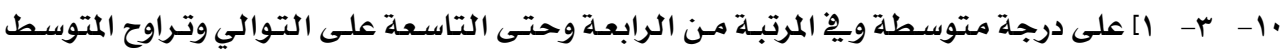

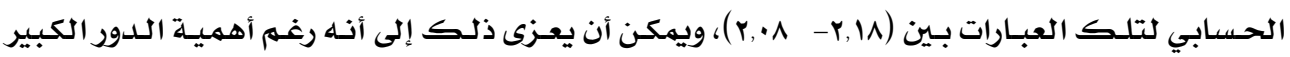

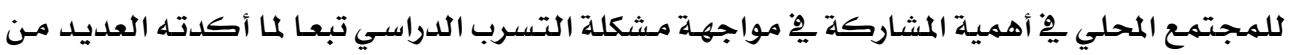

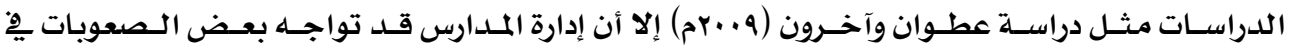

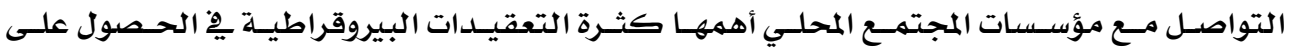
موافقات للقيام بهذا التواصل أو عقد الشراكات المطلوبـة. 


\section{السؤال الثاني وينص على:}

"هل توجد فروق ذات دلالة إحصائية ِِّ تقدير أفراد الدراسة لدور الإدارة المدرسية ِِ مواجهة

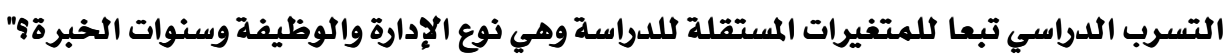

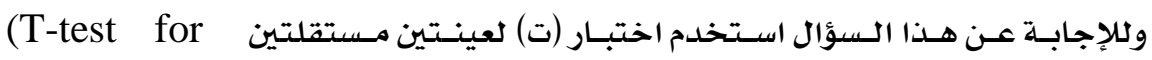

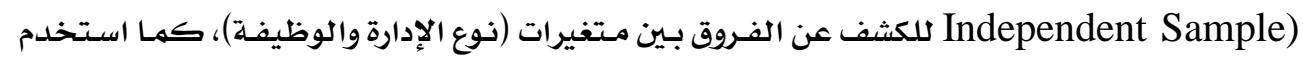

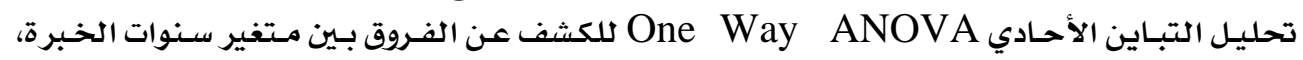

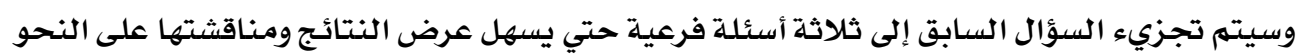
التالي:

أ- " هل توجد فروق ذات دلالة إحصائية يِّ تقدير أفراد الدراسـة لدور الإدارة المدرسية فِيْ

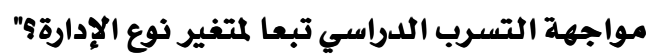

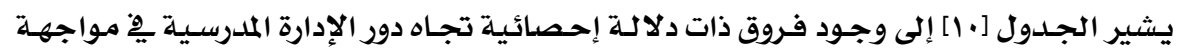

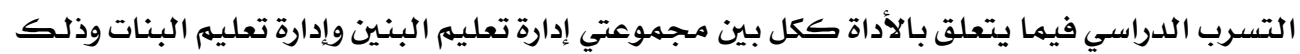

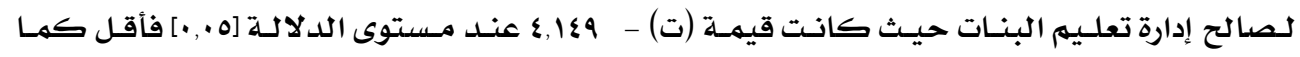

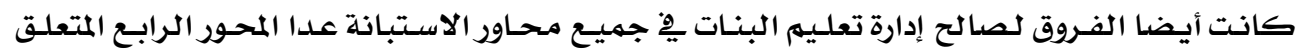
بالمجتهـع المحلي.

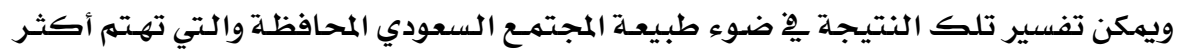

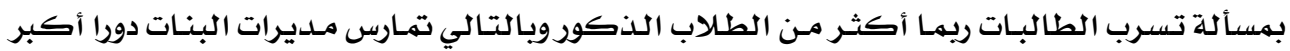

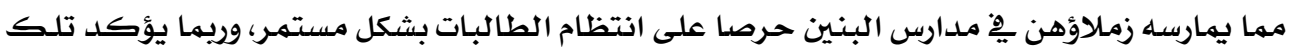

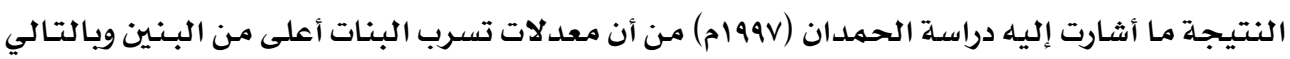

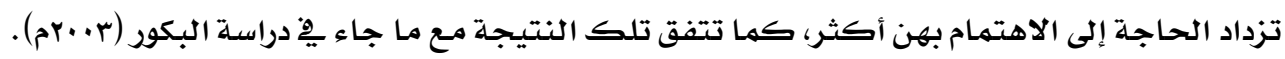
جدول [• ا] قيمة (ت) ومستوى الدلالة لاستجابات أفراد الدراسة تبعا لمتغير نوع الإدارة

\begin{tabular}{|c|c|c|c|c|c|c|c|}
\hline مستوي & $\begin{array}{l}\text { قيهة } \\
\text { (ت) } \\
\end{array}$ & الالمياري & 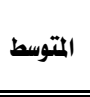 & $\begin{array}{c}\text { علاد } \\
\text { الأفراد } \\
\end{array}$ & المتفيرات & محاور الاستبانة & ? \\
\hline \multirow{2}{*}{$\cdot, \cdots$} & \multirow{2}{*}{0,809} & $\varepsilon, 1 \lambda$. & $\mathrm{r} \xi, \mathrm{YA}$ & $1 . \xi$ & 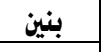 & \multirow{2}{*}{ دور الإدارة المدرسية فيما يتعلق بالتلميذ } & \multirow{2}{*}{1} \\
\hline & & $r, Y \leqslant q$ & $r v, \cdot r$ & int & 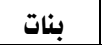 & & \\
\hline \multirow{2}{*}{$\cdot, \cdots$} & \multirow{2}{*}{$\begin{array}{c}- \\
v, r 99 \\
\end{array}$} & r,rYq & rq,or & $1 . \xi$ & بنين & \multirow{2}{*}{ دور الإدارة المدرسية فيما يتعلق بالمعلم } & \multirow{2}{*}{ r } \\
\hline & & i,rv. & $r \Lambda, T r$ & lar & 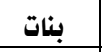 & & \\
\hline \multirow{2}{*}{$\cdot, \cdots$} & \multirow{2}{*}{$0, \$ 10$} & r,q11 & ro, ro & $1 . \xi$ & بنين & \multirow{2}{*}{ دور الإدارة المدرسية فيما يتعلق بالتعاون مع الأسرة } & \multirow{2}{*}{ r } \\
\hline & & $r, r \cdot 0$ & $r Y, \xi Y$ & lar & 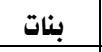 & & \\
\hline \multirow{2}{*}{$\cdot, 917$} & \multirow{2}{*}{$\cdot, 1 \cdot 7$} & $0,07 r$ & $r r, \cdot \xi$ & $1 . \xi$ & 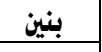 & \multirow{2}{*}{ دور الإدارة المدرسية فيما يتعلق بالمجتمع المحلي } & \multirow{2}{*}{$\varepsilon$} \\
\hline & & 9,019 & $r r, \cdot 1$ & lar & 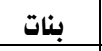 & & \\
\hline \multirow{2}{*}{$\cdot, \cdots$} & \multirow{2}{*}{$\varepsilon, 1 \leqslant 9$} & $\xi \xi, r \cdot r$ & १A, $\mathrm{V \Psi}$ & $1 . \xi$ & 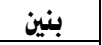 & \multirow{2}{*}{ 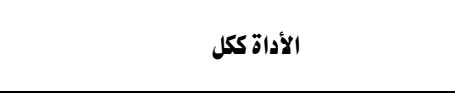 } & \\
\hline & & 11, ov. & $1 \cdot 0,17$ & lar & 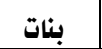 & & \\
\hline
\end{tabular}




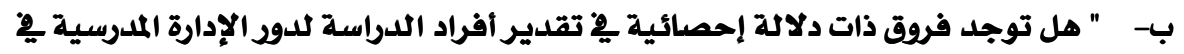

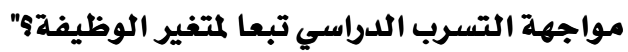

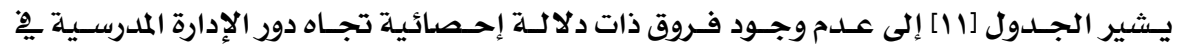

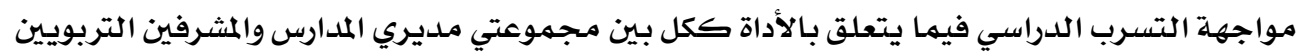

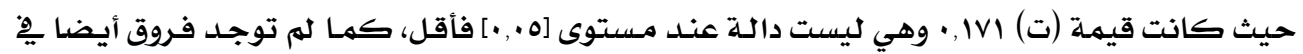

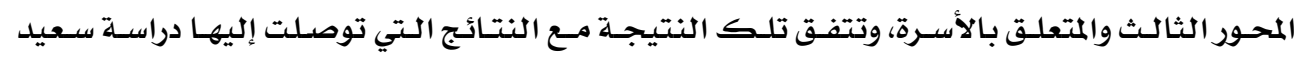

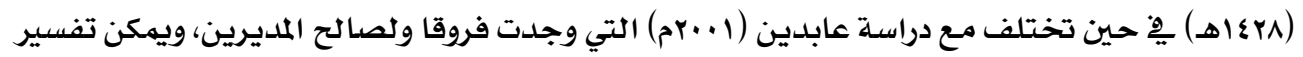

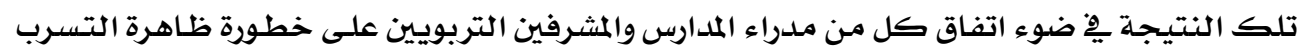

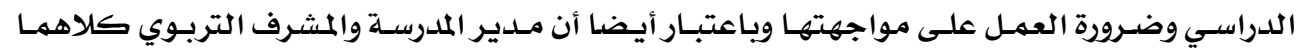

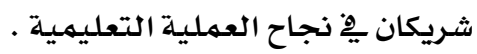

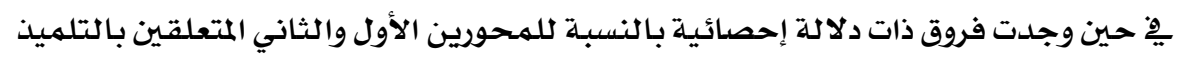

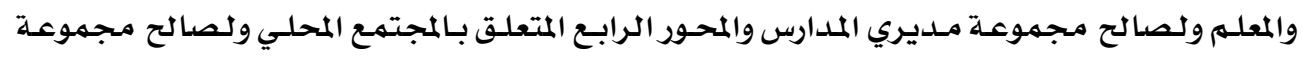
المشرفين.

جدول [11]

قيمة (ت) ومستوى الدلالة لاستجابات أفراد الدراسـة تبعا لمتغير الوظيفة

\begin{tabular}{|c|c|c|c|c|c|c|c|}
\hline مستوي & قيمة (ت) & 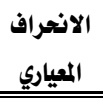 & المتوسط & علاد الأفراد & المتفيرات & محاور الاستبانة & ค \\
\hline \multirow{2}{*}{$\cdot, \cdot 11$} & \multirow{2}{*}{$r, 000$} & $r, \wedge \leqslant r$ & Yq, OZ & r.६ & 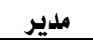 & \multirow{2}{*}{ دور الإدارة المدرسية فيما يتعلق بالتلميذ } & \multirow{2}{*}{1} \\
\hline & & $\{, 779$ & ro, rq & At & 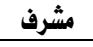 & & \\
\hline \multirow{2}{*}{$\cdot, \cdot \bullet$} & \multirow{2}{*}{$r, 0 \cdot \wedge$} & r, rrT & $r \Lambda, r r$ & $r \cdot \varepsilon$ & 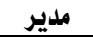 & \multirow{2}{*}{ دور الإدارة الملدرسية فيما يتعلق بالمعلم } & \multirow{2}{*}{ r } \\
\hline & & r,rrq & $r v, \bullet$ & Ar & مشرف & & \\
\hline \multirow{2}{*}{$\cdot, r \leqslant q$} & \multirow{2}{*}{$\cdot, 9 r \wedge$} & $r, \wedge r r$ & rY,Ar & $r \cdot \xi$ & 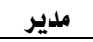 & \multirow{2}{*}{ دور الإدارة المدرسية فيما يتعلق بالتعاون مع الأسرة } & \multirow{2}{*}{$r$} \\
\hline & & $\xi, r \cdot \wedge$ & MY,\&l & Ar & مشرف & & \\
\hline \multirow{2}{*}{$\cdot, \cdot \bullet r$} & \multirow{2}{*}{$r, \cdot 0 \Lambda$} & $7, I Y r$ & rI, rr & $r \cdot \xi$ & 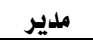 & \multirow{2}{*}{ دور الإدارة المدرسية فيما يتعلق بالمجتمع المحلي } & \multirow{2}{*}{$\varepsilon$} \\
\hline & & $7,|v|$ & rr,Yr & At & مشرف & & \\
\hline \multirow{2}{*}{$\cdot, \wedge \uparrow \varepsilon$} & \multirow{2}{*}{$\cdot|v|$} & $11,7 \mathrm{~F}$ & $1 \cdot r, 9 r$ & $r \cdot \xi$ & مدير & \multirow{2}{*}{ الأداة ككل } & \\
\hline & & $10, \mathrm{AAV}$ & $1 \cdot r, 7 r$ & Ar & مشرف & & \\
\hline
\end{tabular}

ج- "هل توجد فروق ذات دلالة إحصائية يِّ تقدير أفراد الدراسـة لدور الإدارة المدرسية فِية

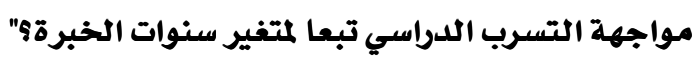

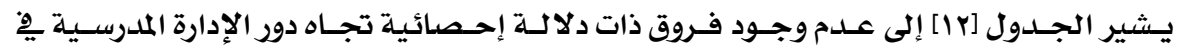

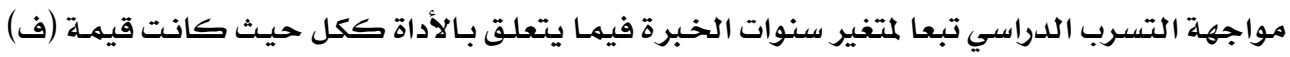

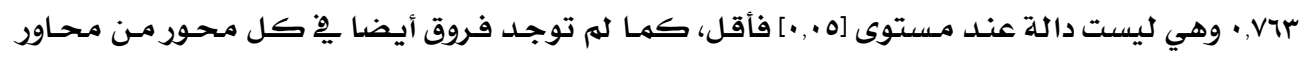

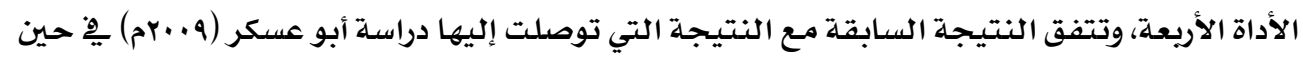




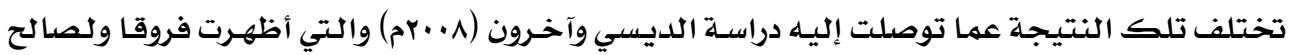
فئة الخبرة الطويلة.

ويهكن أن تعزى تلك النتيجهة إلى أن معظم إدارات المدارس المتوسطة تهـارس أدوارهـا المتعـددة

مِّ العمل على مواجهة ظاهرة التسـرب الدراسـي والحـد منهـا بغض النظـر عن اخـتلاف سـنوات الخـبرة

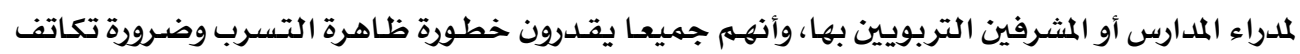

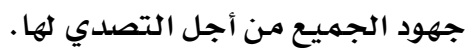

جدول [1,

قيمة (ف) ومستوى الدلالة لاستجابات أفراد الدراسة تبعا لمتغير سنوات الخبرة

\begin{tabular}{|c|c|c|c|c|c|c|c|}
\hline مستوي & قيمة & دالحرية & متوسط & مجموع المربعات & مصدر التباين & محاور الاستبانة & P \\
\hline \multirow{2}{*}{ • } & \multirow{2}{*}{ I,Aro } & $r$ & rr,rys & $\varepsilon \xi, \vee Y q$ & بين المجموعات & \multirow[t]{2}{*}{ دور الإدارة الملدرسية فيها يتعلق بالتلميذ } & \multirow{2}{*}{1} \\
\hline & & rAs & $17,19 \mid$ & $r \leqslant 7 r, I \leqslant r$ & داخل المجموعات & & \\
\hline \multirow{2}{*}{$\cdot, \cdot v 1$} & \multirow{2}{*}{ r, Tro } & $r$ & $11, \cdot \sum \varepsilon$ & $r q, \cdot A \Lambda$ & بين المجموعات & \multirow[t]{2}{*}{ دور الإدارة المدرسية فيما يتعلق بالمعلم } & \multirow{2}{*}{$r$} \\
\hline & & rA\& & $7, \vee \leqslant 0$ & $1910,07 \mathrm{r}$ & داخل المجموعات & & \\
\hline \multirow{2}{*}{ •, 177} & \multirow{2}{*}{$1, \lambda \cdot 7$} & $r$ & r.,ITE & $\varepsilon \cdot, r 79$ & 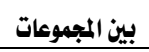 & \multirow{2}{*}{ دور الإدارة المدرسية فيما يتعلق بالتعاون } & \multirow{2}{*}{$r$} \\
\hline & & rAs & $11,1 \leqslant \Lambda$ & r170,971 & داخل المجموعات & & \\
\hline \multirow{2}{*}{ •, VTr } & \multirow{2}{*}{ r } & $r$ & Ir,IVr & $r \xi, r \leqslant \varepsilon$ & 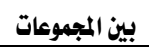 & \multirow{2}{*}{ دور الإدارة الملدرسية فيها يتمقت بالمجتمع } & \multirow{2}{*}{$\varepsilon$} \\
\hline & & rAs & rA, qrE & II.ov,r.r & 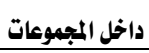 & & \\
\hline \multirow{2}{*}{ •,รT४ } & \multirow{2}{*}{ •,vqr } & $r$ & $\mid r \wedge, \vee r q$ & rov, OAO & بين المجموعات & \multirow{2}{*}{ الأداة ككل } & \\
\hline & & YA\& & $171, v \varepsilon \mid$ & SVArr, rAY & داخل المجموعات & & \\
\hline
\end{tabular}

\section{ملفص النتائج:}

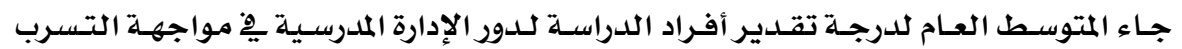
الدراسي مـرتفعا بشكل عام وكذلك يْ ثلاثثة من محساور الدراسـة عدا المحسور الرابـع المتعلـق بـالمجتمـع المحلي والذي جـاء بـرجة مـتوسطة.

وقد احتل المحور الخاص بدور الإدارة المدرسية فيما يتعلق بالمعلهم المرتبـة الأولى، يليه المحوران

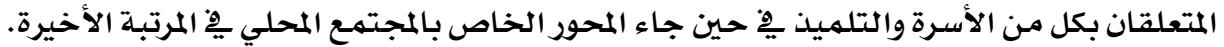
وكشفت الدراسـة عن وجسود فروق ذات دلالـة إحصدائيسة تجـاه دور الإدارة المدرسيـة ٍِِ مواجهـة

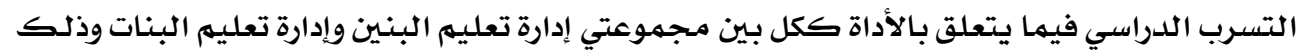
لصالح إدارة تعليه البنات. لكرئ

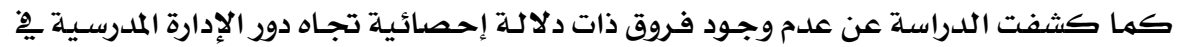
مواجهة التسـرب الدراسي فيما يتعلق بـالأداة ككل تبعا لمتغيري الوظيفة وسنوات الخبرة. 


\section{توصيات البحث وهقترحاته:}

ِِِ ضوء النتائج التي توصل إليها البحث، فيما يلي عدد من التوصيات والمقترحات

\section{أولا: توصيات ترتبط بلدور إدارة الملدرسة :}

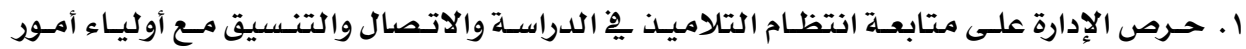

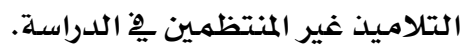

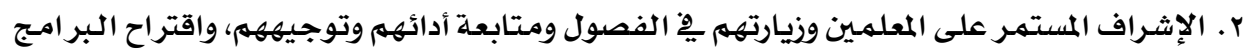

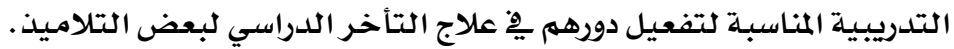

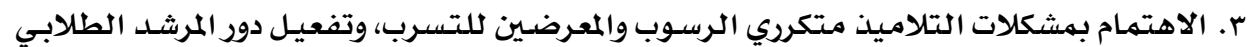

ع بِّ علاجها.

ع. التخطيط للأنشطة اللاصفية التي تعزز مشاركة التلاميذ ِِّ العمليـة التعليميـة، مـع تنظيم

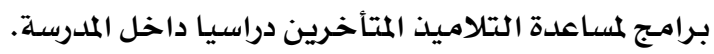

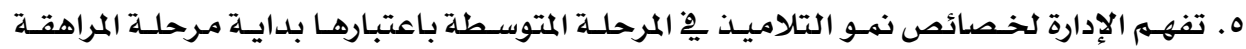

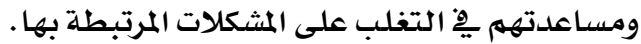

T. تحليل مؤشرات نجاح التلاميذ للتعرف على المشكلات التعليميـة للطلاب الراسبين والمعرضـين

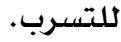

V. تكامل أدوار جميع العاملين بالمدرسة لحل مشكلات الطلاب بالتنسيق مع أولياء أمور التلاميذ.

ثانيا: توصيات تتعلق بلدور المعلم :

ا ـ حـرص المعلـم علسى تـوفير بيئسة صـفية تعـزز عمليـة الـتعلهم داخـل الـصف، والاهتمـام بتحقيـق

الانضباط الصفي لضمان استفادة جميع التلاميذ.

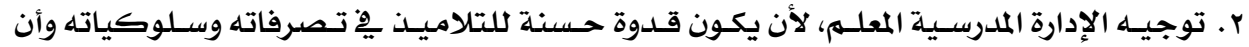

يحرص على حسن معاملتهم. بوحئ.

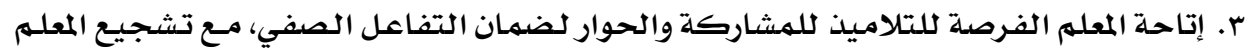

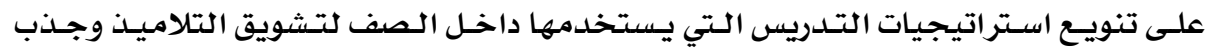

انتباههم.

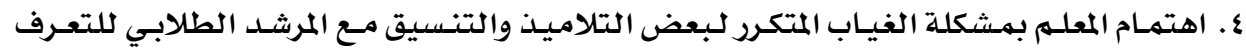

$$
\text { على أسباب وعوامل تلك املم المثكلة. }
$$

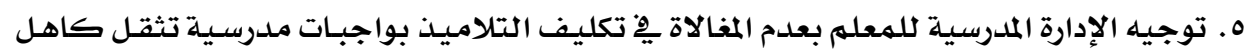

هؤلاء التتلاميذ.

T. حرص المعله على إيجاد المنافسة الشريفة بين التلاميذ لتفعيل مشاركتهم داخل الصف.

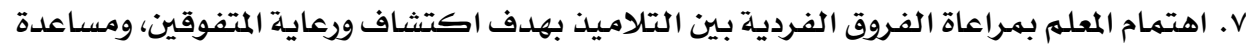

التلاميذ المتأخرين دراسيا. 
ثالثا: توصيات ترتبط بتفعيل التعاون بين المدرسة والأسرة والمجتمع المحلي: ا ـ تشجيع الإدارة المدرسية أولياء أمور التلاميذ على متابعة التقدم الدراسي لأبنائهم.

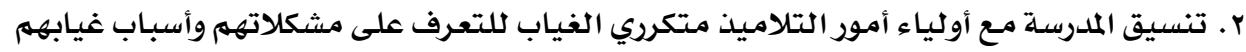

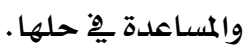

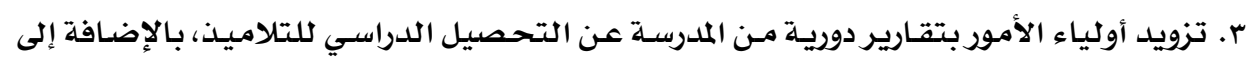

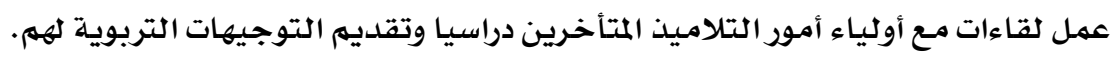

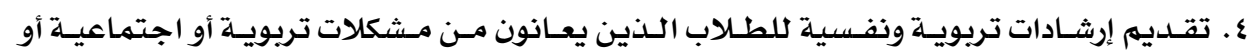
نفسية.

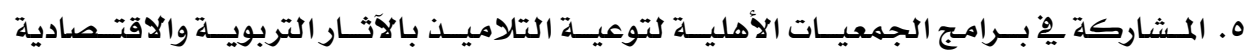

$$
\text { والاجتهاعية المترتبـة على التسرب الدربـ الدراسي. }
$$

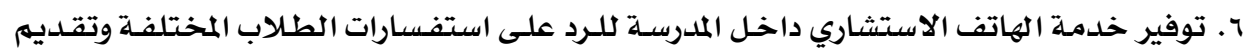

$$
\text { التوجيهات لهم. }
$$

\section{رابعا: دراسات وبحوث مقترحة:}

ا ـ دراسـة دور الإدارة المدرسية ِِّ مواجهة التسرب الدراسي ِِّ المرحلة الابتدائية أو المرحلة الثانوية.

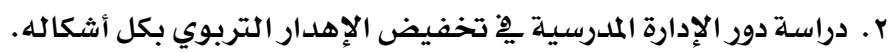

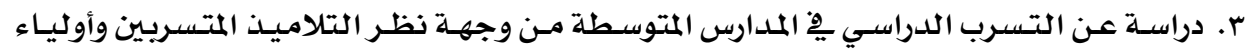
أمورهم. 


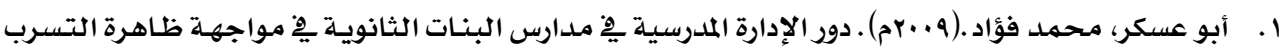

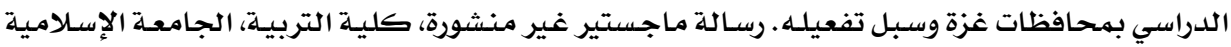
بغزة: فلسطين.

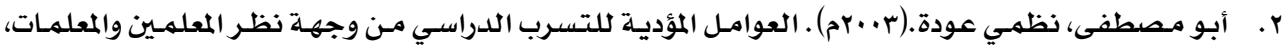

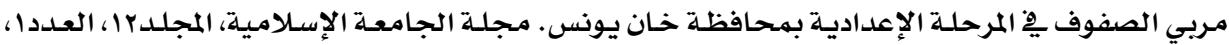
\&0. - \& $\vee$

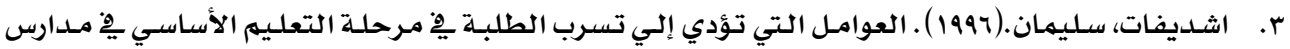

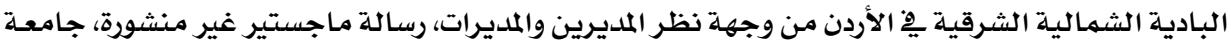

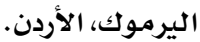

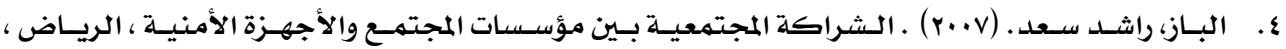

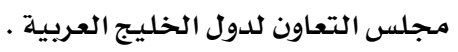

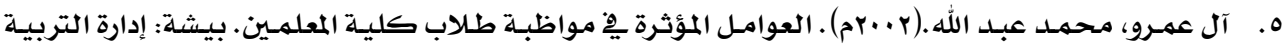
والتعليم، المملكة العربية السعودية.

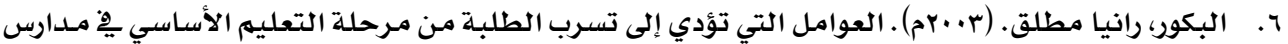
تربيـة الأغوار الجنوبيـة مـن وجهـة نظر مـديري المدارس والمعلمـين والمرشدين التربويين. رسـالة الماجستير، جامعة الفاشر: السودان.

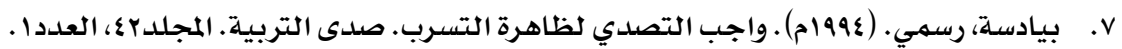

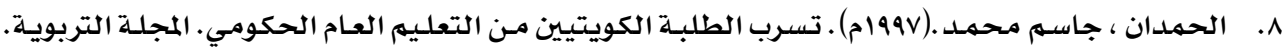

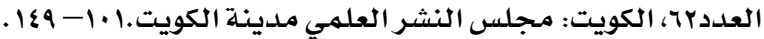

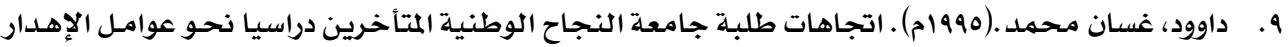
التعليمي الجامعي. رسالة ماجستير غير منشورة، جامعة النجاح الوطنية، نابلس.

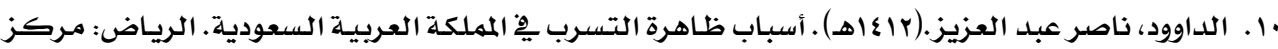
أبحاث مكافحة الجريمة بوزارة الداخلية.

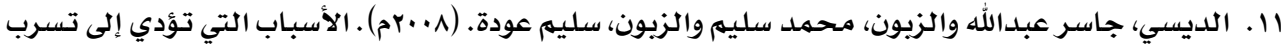

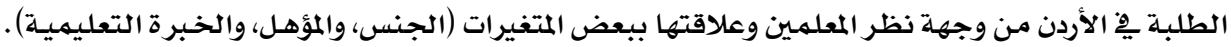

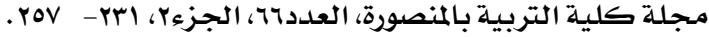

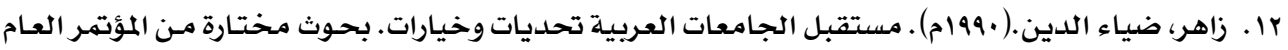

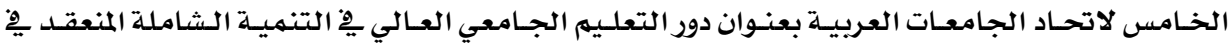
جامعة عدن، عدن. 


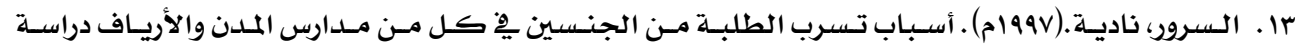

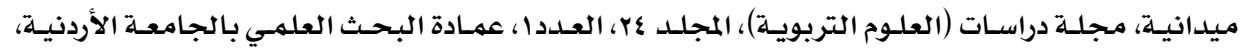
عمان،

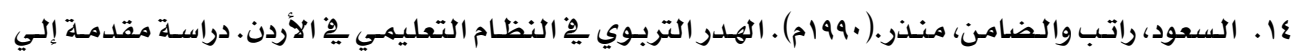
مؤتمر الإهدار التربوي واقتصاديات التعليه، عمان.

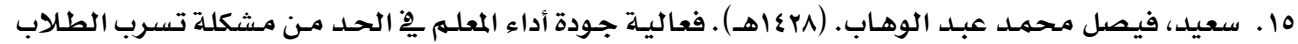
كما يراها مشرفو ومعلمو المرحلة الابتدائية بمنطقة الباحة التعليميلة. مقدم للقاء السنوي الرابع عشر

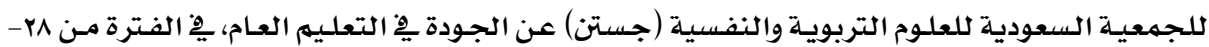
. $1 \leqslant Y \Lambda / \xi / Y q$

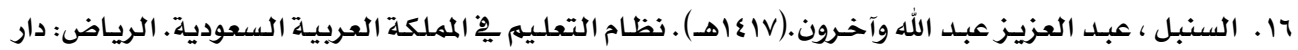

$$
\text { الخريجي للنشر والتوزيع. }
$$

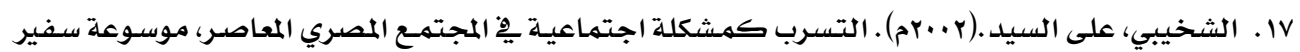

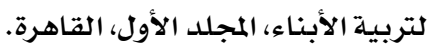

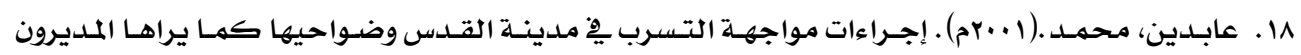

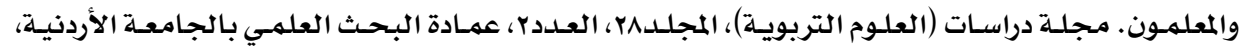

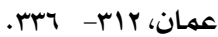
19 . عبدالله، غسـان. (1990م) . ظاهرة التسرب وانعكاسـاتها على الشعب الفلسطيني. رام الله: مركز الدراسـات التطبيقية.

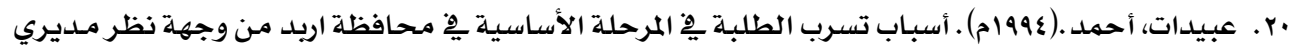

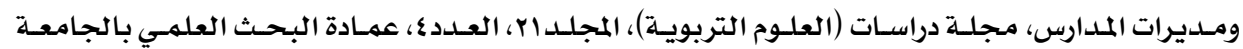

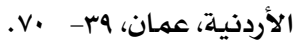

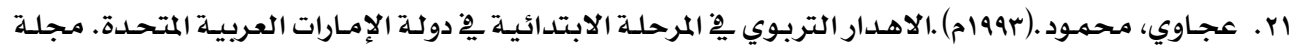
كلية التربية، جامعة الإمارات،مجلد ^،العدد 9.

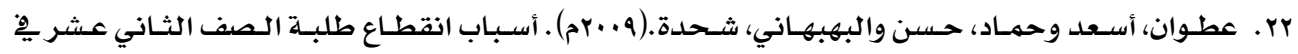

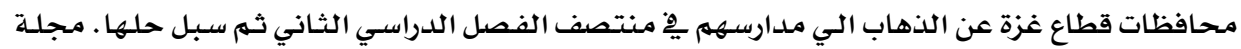

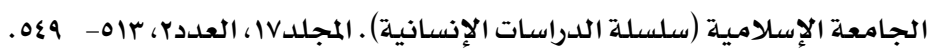

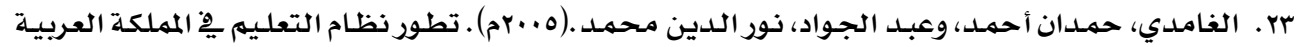
السعودية. طب، الرياض: مكتبـة الرشد.

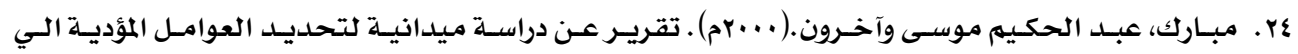
ظاهرتي الرسوب والتسـرب بـين طلاب جامعـة أم القـرى مـن وجهـة نظـر الراسبيـن والمتسـربين وأعضاء هيئسة

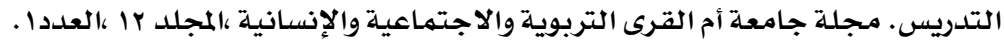

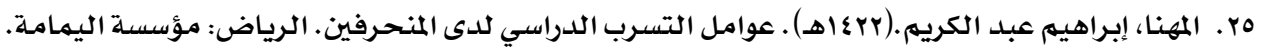


26. Bucci, J. \& Reitzammer, A. (1992) Teachers make the critical differences in dropout prevention, Educational Forum, No.57, pp63-70.

27. De Saw, Semous (1999) High school dropouts: implications in the economic development of West Virginia. Research paper 9909 ERIC No. 43012.

28. Ferris, J (1993) Disadvantaged students in university: an analysis of attrition rates and patterns at the university of Toronto. Dissertation Abstracts, AAC MM4119, MA Degree, University of Toronto, Canada.

29. Kalyus, Richard (2001) Secondary school completion and dropout in Texas public school, ERIC No.: ED457282. 